\title{
T cells establish and maintain CNS viral infection in HIV-infected humanized mice
}

\author{
Jenna B. Honeycutt, ${ }^{1}$ Baolin Liao, ${ }^{1,2}$ Christopher C. Nixon, ${ }^{1}$ Rachel A. Cleary, ${ }^{1}$ William O. Thayer, ${ }^{1}$ Shayla L. Birath, ${ }^{1}$ \\ Michael D. Swanson, ${ }^{1}$ Patricia Sheridan, ${ }^{3}$ Oksana Zakharova, ${ }^{1}$ Francesca Prince, ${ }^{1}$ JoAnn Kuruc, ${ }^{1}$ Cynthia L. Gay, ${ }^{1}$ \\ Chris Evans, ${ }^{1}$ Joseph J. Eron, ${ }^{1}$ Angela Wahl, ${ }^{1}$ and J. Victor Garcia ${ }^{1}$
}

'Division of Infectious Diseases, Center for AIDS Research (CFAR), University of North Carolina at Chapel Hill (UNC-CH), School of Medicine, Chapel Hill, North Carolina, USA. ${ }^{2}$ Department of Infectious Diseases, Guangzhou Eighth People's Hospital, Guangzhou Medical University, Guangzhou, Guangdong, China. ${ }^{3}$ Department of Nutrition, UNC-CH, Gillings School of Global Public Health, Chapel Hill, North Carolina, USA.

\begin{abstract}
The human brain is an important site of HIV replication and persistence during antiretroviral therapy (ART). Direct evaluation of HIV infection in the brains of otherwise healthy individuals is not feasible; therefore, we performed a large-scale study of bone marrow/liver/thymus (BLT) humanized mice as an in vivo model to study HIV infection in the brain. Human immune cells, including $\mathrm{CD}^{+} \mathrm{T}$ cells and macrophages, were present throughout the BLT mouse brain. HIV DNA, HIV RNA, and/or p24 ${ }^{+}$cells were observed in the brains of HIV-infected animals, regardless of the HIV isolate used. HIV infection resulted in decreased numbers of $C D 4^{+} \mathrm{T}$ cells, increased numbers of $\mathrm{CD8} 8^{+} \mathrm{T}$ cells, and a decreased $\mathrm{CD4} 4^{+} / \mathrm{CD8} 8^{+} \mathrm{T}$ cell ratio in the brain. Using humanized T cell-only mice (TOM), we demonstrated that T cells establish and maintain HIV infection of the brain in the complete absence of human myeloid cells. HIV infection of ToM resulted in CD4+ $T$ cell depletion and a reduced CD4 ${ }^{+} /$ CD8 ${ }^{+} \mathrm{T}$ cell ratio. ART significantly reduced HIV levels in the BLT mouse brain, and the immune cell populations present were indistinguishable from those of uninfected controls, which demonstrated the effectiveness of ART in controlling HIV replication in the CNS and returning cellular homeostasis to a pre-HIV state.
\end{abstract}

\section{Introduction}

The advent and widespread use of effective antiretroviral therapy (ART) to treat HIV infection has dramatically curtailed the severity of the neurocognitive impairment previously observed in HIV-infected patients (1). However, neurological manifestations are still present in a number of patients (2-5). The continued, albeit ameliorated, presence of these neurocognitive deficiencies suggests that despite treatment, HIV infection may have an ongoing deleterious effect on the CNS. Alternatively, neurocognitive impairment may result from damage caused during the initial infection of the CNS that persists but is not progressive.

In 2015, two different groups demonstrated that the CNS has a functional lymphatic system that drains cerebral spinal fluid (CSF) into the deep cervical lymph nodes $(6,7)$. The discovery of a functional meningeal lymphatic system underscores the need for model systems to study the interactions between the peripheral immune system and the CNS during HIV infection. This is important, as the meningeal lymphatic system would represent a potential path for HIV in the brain to re-enter the periphery. This might be especially problematic in individuals who are infected with macrophage-tropic HIV, as the brain contains a large number of microglia (a brain-specific macrophage population), which could

Authorship note: $\mathrm{BL}$ and CCN contributed equally to this work. Conflict of interest: The authors have declared that no conflict of interest exists. Submitted: December 4, 2017; Accepted: April 10, 2018.

Reference information: J Clin Invest. 2018;128(7):2862-2876.

https://doi.org/10.1172/JCI98968. readily restart systemic HIV disease if therapy were interrupted or if ART-resistant viruses were present in the CNS. However, the majority of individuals are infected with $\mathrm{T}$ cell-tropic viruses (8, 9), which have a limited ability to replicate in myeloid-derived cells. A study of the CSF of patients during early HIV infection revealed that the viruses in the CSF had an entry phenotype consistent with infection of $\mathrm{T}$ cells only and remained $\mathrm{T}$ cell tropic through the first 2 years of infection (10). Interestingly, some compartmentalization was observed, in which viruses in the CSF were distinct from those in the blood, although these CNS-derived viruses retained their specificity for T cells. In a subset of patients with CNS virus compartmentalization, the viruses in the CSF are able to infect cells with a low CD4 density, suggestive of macrophage tropism (11-14). This is associated with the duration of infection and suggests that macrophage-tropic viruses may evolve over time within an individual.

Although several neurological diseases are associated with increased numbers of $\mathrm{T}$ cells trafficking into the brain, such as herpes simplex virus infection or multiple sclerosis (15-18), there is evidence that deficits in the $\mathrm{T}$ cell compartment or prevention of $\mathrm{T}$ cell trafficking into the CNS has detrimental outcomes for memory and learning (19-21) and may increase disease severity during viral infection (West Nile virus in CCR5 deletion homozygotes; ref 22). The presence of IFN- $\gamma$-expressing $\mathrm{CD}^{+} \mathrm{T}$ cells in the CSF of HIV-infected patients is associated with an increased risk of HIV-associated neurocognitive disorders (HAND) (23), suggesting a potential role for lymphocyte trafficking in neurocognitive impairment. There is also evidence to suggest that a con- 
A

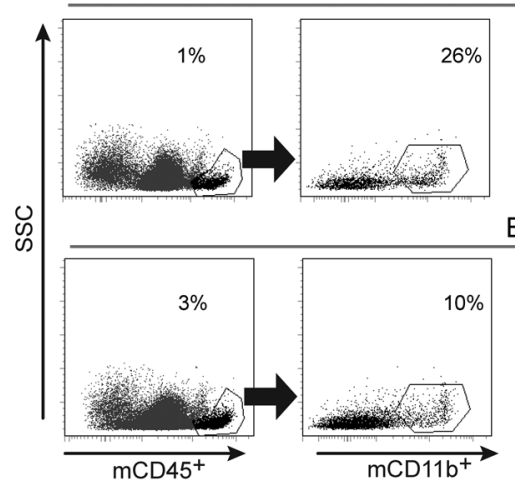

B

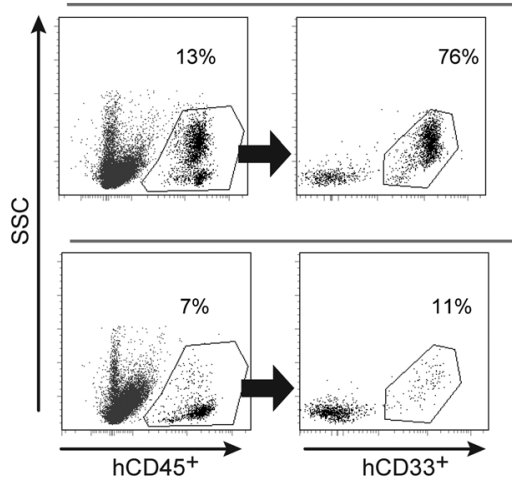

Balb/c mouse no. 1

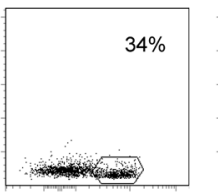

Balb/c mouse no. 2

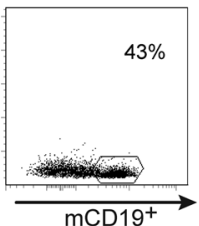

BLT mouse no. 1

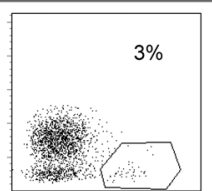

BLT mouse no. 2

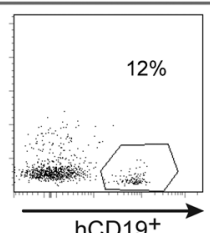

BLT mice nos. 3 and 4

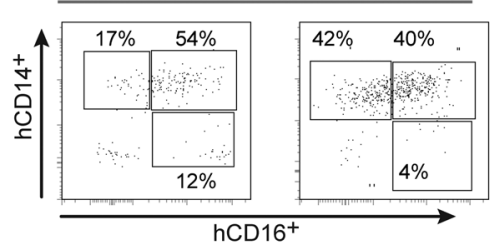

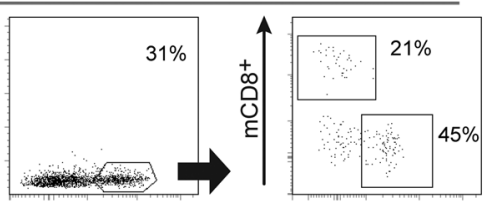
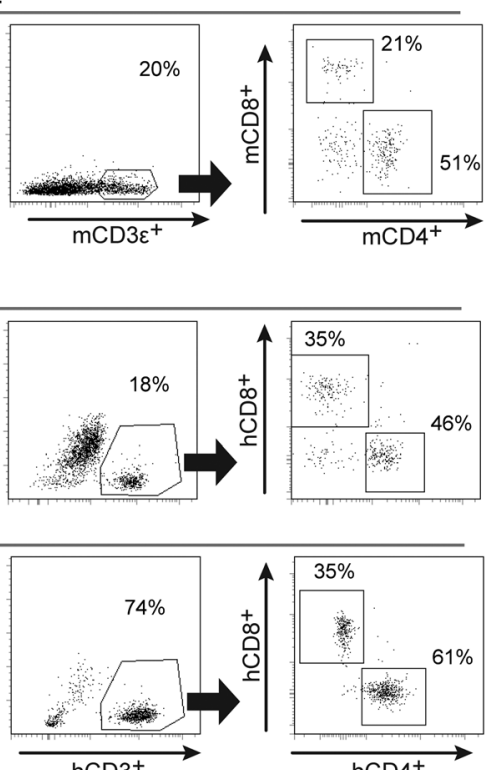

$\mathrm{hCD}^{+}$
Figure 1. Hematopoietic cells are present in the brains of WT and BLT humanized mice. (A) Flow cytometric analysis revealed the presence of murine hematopoietic cells ( $\left.\mathrm{mCD} 45^{+}\right)$in the brains of BALB/c mice. Murine myeloid cells $\left(m C D 11 b^{+}\right), B$ cells (mCD19+), and T cells (mCD3 $\varepsilon^{+}$), including $\mathrm{CD}^{+}$and $\mathrm{CD} 8^{+} \mathrm{T}$ cell subsets, were present. (B) Representative flow cytometric plots from 2 of the BLT mice in Figure 2A demonstrating the presence of human hematopoietic cells (hCD45'), myeloid cells (hCD33+), B cells (hCD19'), and T cells (hCD3+), including CD4 ${ }^{+}$and $C D 8^{+} T$ cell subsets. (C) Phenotypic characterization of the human macrophages in the brains of BLT mice showed the presence of classical (CD14+CD16-), intermediate (CD14+CD16 $)$, and nonclassical (CD14 $\left.{ }^{\text {dim }} \mathrm{CD}^{2} 6^{+}\right)$macrophages (gating for hCD45+hCD11b+CD33+ cells). trolled migration of $\mathrm{T}$ cells across the blood-brain barrier occurs as a part of normal neuroimmune surveillance (24-26). As the levels of $\mathrm{CD}^{+}$and $\mathrm{CD}^{+} \mathrm{T}$ cells are greatly altered in immune and mucosal tissues during HIV infection (27-29), it will be important to closely monitor the possible changes in the $\mathrm{T}$ cell populations present in the CNS throughout infection. In humans, studies of the CNS are limited to autopsy samples, noninvasive imaging, and/or sampling of the CSF as a proxy for brain tissue. In order to address specific questions about HIV infection of the CNS in vivo with defined endpoints and controlled experimental design, animal models of infection are needed. To this effect, studies of HIV infection in humanized mice have been extensively used to answer basic questions regarding HIV transmission, pathogenesis, and treatment and cure strategies (30-33).

The presence of HIV and HIV-associated pathologies in the brain have been reported for several humanized mouse models to date $(34,35)$. In the SCID-HIVE mouse model, created by directly injecting HIV-infected macrophages into the brain $(36,37)$, profound encephalitis is observed, accompanied by deficits in learning and memory $(38,39)$. Treatment with ART reduces pathology $(38,40,41)$, suggesting that controlling viral replication is key to minimizing the severe neuropathology otherwise observed.
Other humanized mouse models used to study neuroHIV infection are created by the transplantation of human cells, either peripheral blood mononuclear cells (PBMCs) or CD $34^{+}$hematopoietic stem cells, into immunodeficient mice. HIV-infected human $\mathrm{T}$ cells were observed in the meninges and cortex of HIV-infected human PBMC-transplanted (hPBMC-transplanted) mice along with microgliosis and neuronal dropout (42). In humanized NSG (hNSG) mice, a CD34+ stem cell-reconstituted model, HIV RNA was detected in the brains of a portion of HIV-infected mice, although the levels of HIV DNA were below the limit of detection (43). In a model reconstituted with human myeloid cells but not $\mathrm{T}$ cells (myeloid-only mice $[\mathrm{MoM}]$ ), increased numbers of macrophages were observed in the brains of HIV-infected animals compared with numbers in uninfected controls, and infected macrophages were observed throughout the brain (32). While several types of humanized mice exist, the bone marrow/liver/thymus (BLT) humanized mouse model is unique, in that human $\mathrm{T}$ cells in these mice are educated in the context of HLA through implantation of human thymic tissue. The presence of HIV-infected T cells and macrophages was detected in the brains of BLT mice infected with an HIV-1 chimeric strain (NL4-3 env ADA -IRES-GFP) (44). Additionally, HIV-1 pol RNA and DNA were detected in the brains 
Table 1. Characteristics of the humanized mice studied

\begin{tabular}{|c|c|c|c|c|c|c|c|c|c|c|c|}
\hline Figure & $\begin{array}{l}\text { Figure } \\
\text { panel }\end{array}$ & Model & $\begin{array}{l}\text { Total } \\
(n)\end{array}$ & $\begin{array}{l}\text { No. and sex } \\
\text { of mice }\end{array}$ & $\begin{array}{l}\text { Irradiation } \\
\text { (n) }\end{array}$ & $\begin{array}{l}\text { Weeks after } \\
\text { humanization } \\
\text { (range) }\end{array}$ & $\begin{array}{c}\% \text { hCD45 } \\
\text { in PB } \\
\text { (range) }\end{array}$ & $\begin{array}{l}\text { Virus } \\
(n)\end{array}$ & $\begin{array}{l}\text { Weeks of } \\
\text { infection } \\
\text { (range) }\end{array}$ & $\begin{array}{l}\text { ART treatment } \\
(n)\end{array}$ & $\begin{array}{c}\text { Weeks of } \\
\text { ART } \\
\text { (range) }\end{array}$ \\
\hline 1 & $B-D$ & BLT & 4 & $4 \mathrm{~F}$ & $2.0 \mathrm{~Gy}(4)$ & $28(26-31)$ & $64 \%(40-75)$ & & & & \\
\hline 5 & A-F (infected) & BLT & 132 & $\begin{array}{l}120 \mathrm{~F} \\
12 \mathrm{M}\end{array}$ & $\begin{array}{l}2.0 \mathrm{~Gy}(70) \\
2.5 \mathrm{~Gy}(50) \\
3.0 \mathrm{~Gy}(12)\end{array}$ & $\begin{array}{l}\text { Pre-HIV: } 21(11-32) ; \\
\text { total: } 28(18-60)\end{array}$ & $67 \%(24-90)$ & $\begin{array}{c}\text { ADA (5) } \\
\text { CHO40 (28) } \\
\text { JR-CSF (73) } \\
\text { LAI (6) } \\
\text { RHPA (7) } \\
\text { THRO (13) }\end{array}$ & $7.3(1.2-31)$ & & \\
\hline \multirow[t]{2}{*}{6} & $A-G$ (uninfected) & ToM & 14 & $\begin{array}{l}11 \mathrm{~F} \\
3 \mathrm{M}\end{array}$ & $\begin{array}{l}2.0 \text { Gy (9) } \\
2.5 \text { Gy (5) }\end{array}$ & $37(18-48)$ & $25 \%(11-62)$ & & & & \\
\hline & A (image) & ToM & 1 & $1 \mathrm{~F}$ & $2.0 \mathrm{~Gy}(1)$ & 34 & $65 \%$ & & & & \\
\hline 7 & D-I (uninfected) & BLT & 104 & $\begin{array}{l}81 \mathrm{~F} \\
23 \mathrm{M}\end{array}$ & $\begin{array}{c}0 \mathrm{~Gy}(2) \\
2.0 \mathrm{~Gy}(60) \\
2.5 \mathrm{~Gy}(41) \\
3.0 \mathrm{~Gy}(1)\end{array}$ & $26(5-41)$ & $68 \%(28-95)$ & & & & \\
\hline
\end{tabular}

The humanized mouse model and the total number of mice are listed for each group by figure and panel. For each experimental group, the sex of the mice (F, female; $M$, male), the level of irradiation used for preconditioning, the viruses used for exposures, the length of infection (weeks), the treatment with ART and the length of treatment are shown for each relevant group.

of HIV-infected BLT mice, and the levels could be reduced by ART (44). Recently, we demonstrated that HIV RNA levels in the brain can be further reduced when ART is administered in combination with the Tat inhibitor didehydro-cortistatin A (45).

Here, we sought to elucidate the kinetics of the cellular and viral changes that occur in the CNS during HIV infection using BLT humanized mice. To this end, we conducted a large-scale, cross-sectional analysis of uninfected, HIV-infected, and HIVinfected/ART-treated mice. We evaluated immune cell populations and HIV levels in the brain. To increase the relevance of our studies to human disease, the animals used in this study represented more than 50 human tissue donors and were infected with clinically relevant HIV isolates and transmitted/founder (T/F) viruses, encompassing both $\mathrm{T}$ cell-tropic and macrophage-tropic strains (32). By minimizing blood contamination of our mouse brain samples via transcardial perfusion at necropsy, we ensured that our observations were tailored to examine the brain tissue rather than vasculature within the brain. Using $\mathrm{T}$ cell-only humanized mice (ToM), we also evaluated the role of human T cells in trafficking HIV to the CNS and maintaining infection in the brain in the com- 

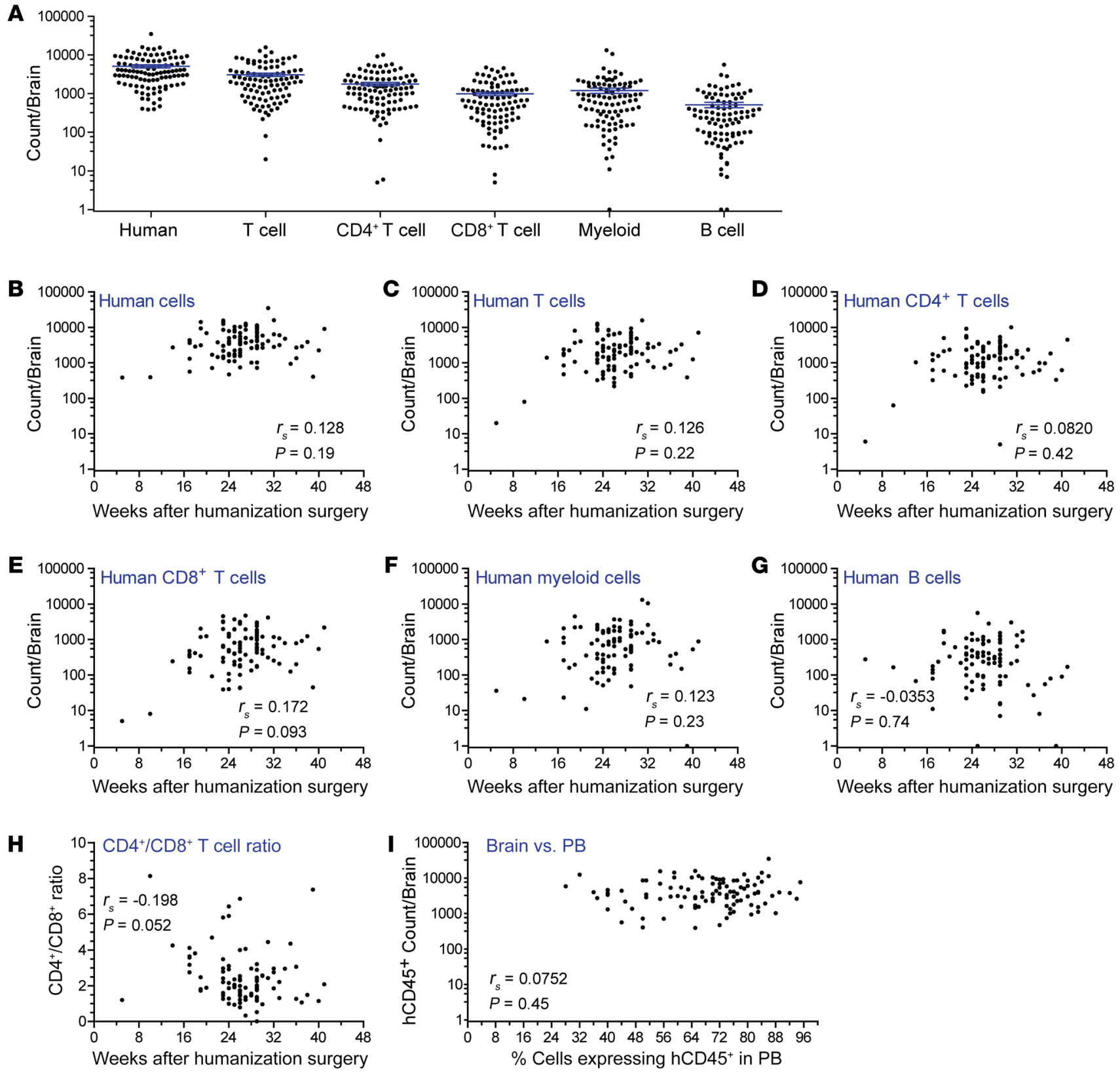

Figure 2. Sustained reconstitution of the BLT mouse brain with human immune cells. (A) Total numbers of human hematopoietic cells, $T$ cells, CD4+ $T$ cells, CD8 ${ }^{+}$T cells, myeloid cells, and B cells in the brains of BLT mice $(n=104)$. Brains were harvested from BLT mice 5 to 41 week after humanization surgery, and flow cytometry was performed to determine the numbers of human immune cells present. Horizontal lines in A indicate the mean \pm SEM. Scatter plots depict the total numbers of human (B) hematopoietic cells $(n=104)$, (C) T cells $(n=97)$, (D) CD4+ T cells $(n=97)$, (E) CD8 ${ }^{+}$T cells $(n=97),(\mathbf{F})$ myeloid cells $(n=97)$, (G) B cells $(n=94)$. (H) Scatter plot shows the CD4+/CD8+ ratio $(n=97)$ in the brain and the post-humanization surgery time points at which analysis was performed. (I) Scatter plot depicts the absolute number of human $\mathrm{CD} 45^{+}$cells in the brain and the percentage of human CD45 cells in the peripheral blood (PB) of BLT mice $(n=103)$ at necropsy. A Spearman's rank correlation test was used to analyze the data in $\mathbf{B}-\mathbf{I}$, and $P$ values are indicated on the individual graphs.

plete absence of human myeloid cells. This study demonstrates that rapid cellular and viral changes occur in the CNS following HIV infection and suggests a strong role for T cells in the establishment and maintenance of HIV infection in the brain.

\section{Results}

The brains of BLT humanized mice are repopulated with human hematopoietic cells. We used BALB/c mice to determine the presence of hematopoietic cells in the normal brain. Specifically, we prepared single-cell suspensions of brain tissue from perfused mice and used polychromatic flow cytometry to evaluate the overall abundance of mouse hematopoietic cells. Our results showed the presence of mouse myeloid, $\mathrm{B}$, and $\mathrm{T}$ cells, including both $\mathrm{CD} 4^{+}$and $\mathrm{CD} 8^{+}$ $\mathrm{T}$ cell subsets, in the brain (Figure 1A and Supplemental Figure 1; supplemental material available online with this article; https://doi. org/10.1172/JCI98968DS1). For this analysis, we focused exclusively on the hematopoietic cells expressing high levels of murine CD 45 (mCD45). Since mice are naturally refractory to HIV infection and 
A

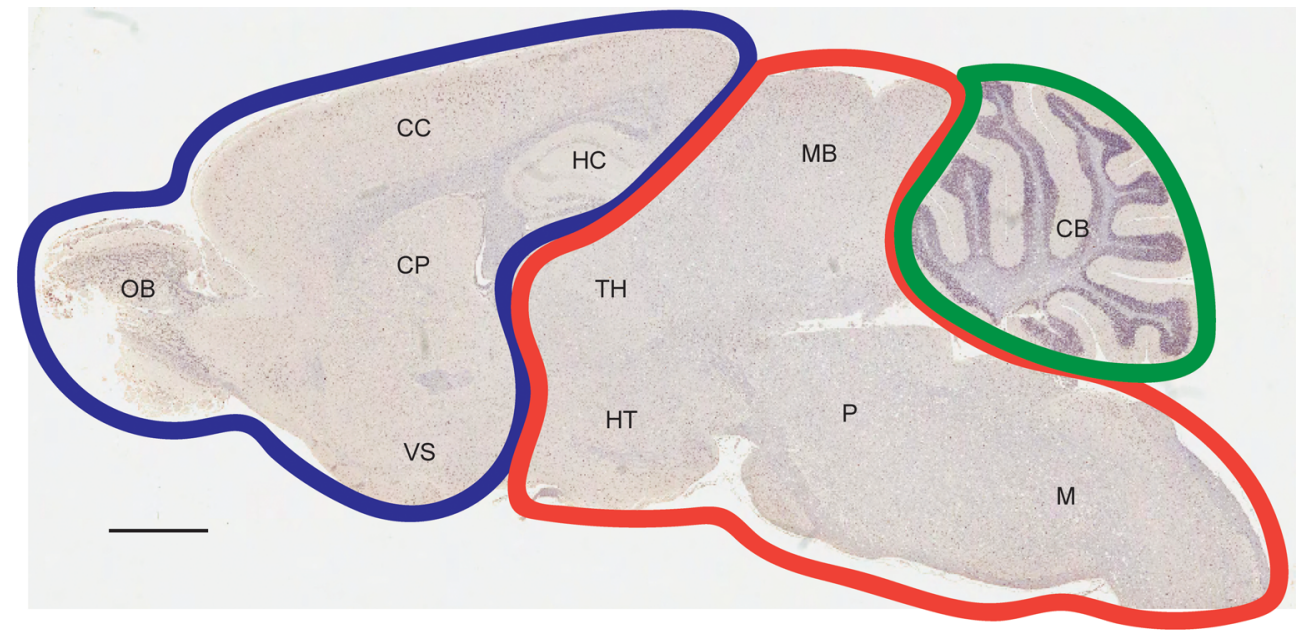

B

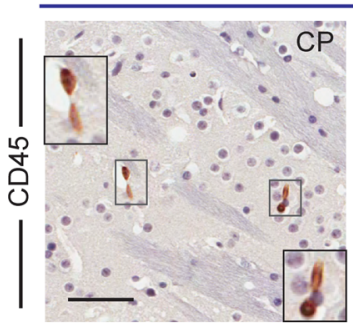

Cerebrum
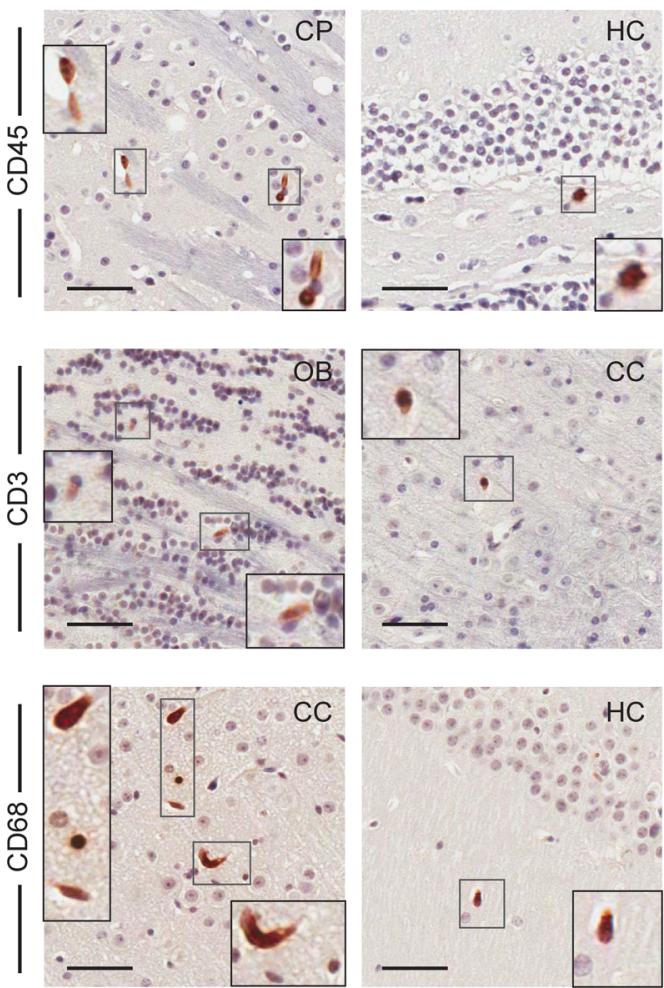
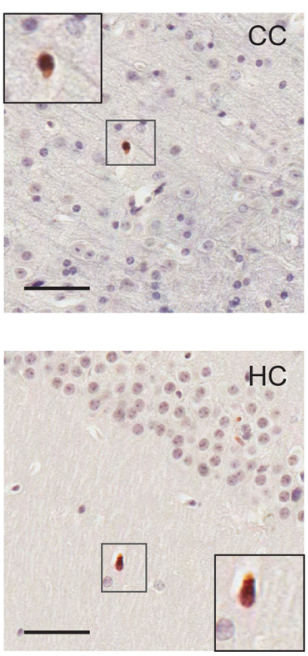

Brain stem
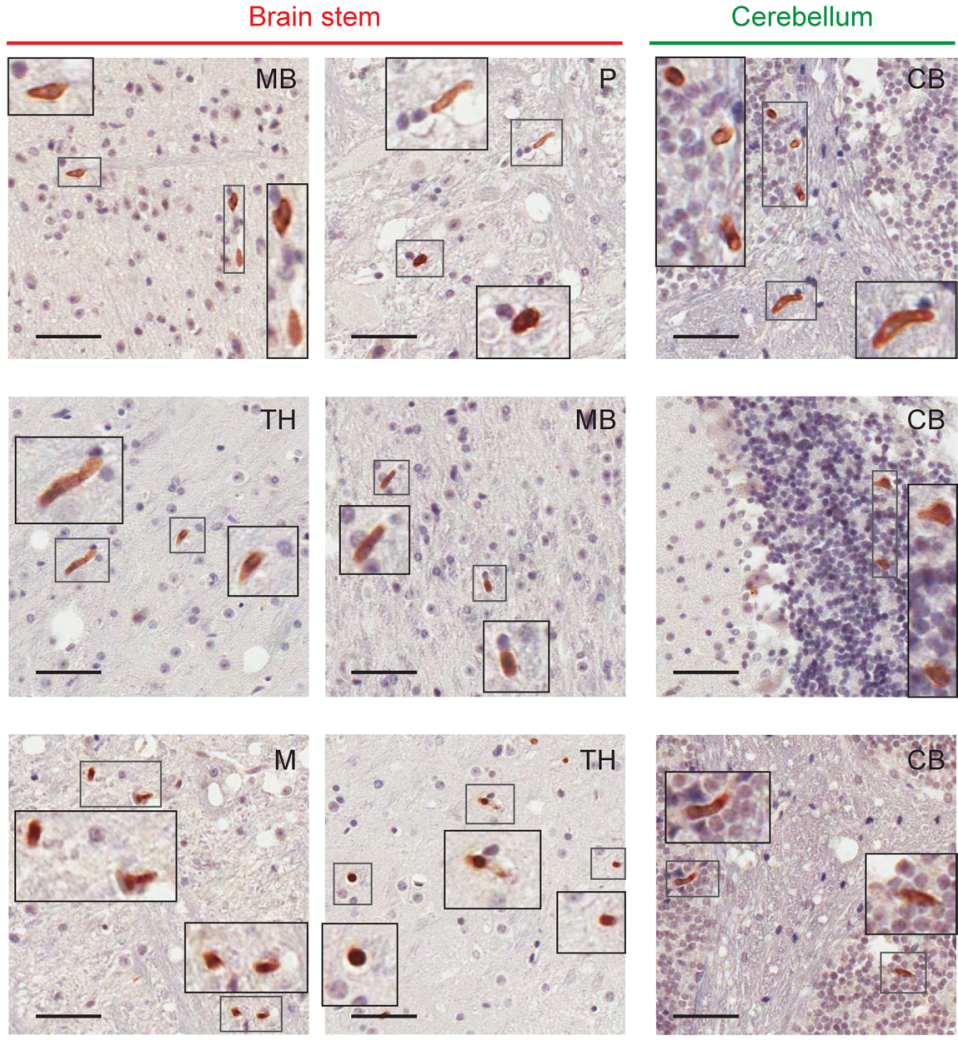

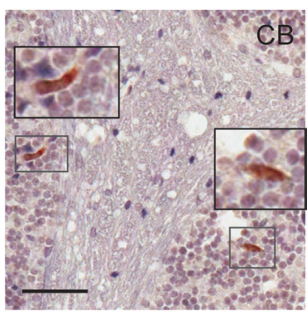

Figure 3. Human immune cells are distributed throughout the brains of BLT mice. (A) The presence of human immune cells in the cerebrum (blue), brain stem (including midbrain, interbrain, and hindbrain, red), and cerebellum (green) of brains harvested from BLT mice was analyzed using IHC. A sagittal section of a BLT mouse brain was stained for hCD45. Scale bar: $1 \mathrm{~mm}$. (B) Brain sections from BLT mice were stained with antibodies specific for human hematopoietic cells (hCD45), T cells (hCD3), and macrophages (hCD68). Scale bars: $50 \mu \mathrm{m}$. Original magnification, $\times 2$ (insets). Positive cells are stained brown. CB, cerebellum; CC, cerebral cortex; CP, caudate putamen; HC, hippocampus; $\mathrm{HT}$, hypothalamus; M, medulla; MB, midbrain, OB, olfactory bulb; P, pons; TH, thalamus; VS, ventral striatum.

cannot be used for HIV research, we wanted to address whether the brains of BLT humanized mice are repopulated with human hematopoietic cells. A description of all humanized mice used for the study are detailed in Table 1 . As in the brains of wild-type (WT) mice, we observed the presence of myeloid, B, and T cells, including both $\mathrm{CD} 4^{+}$ and $\mathrm{CD}^{+} \mathrm{T}$ cells, in the brains of BLT mice, except that the hematopoietic cells in the brains of BLT mice were of human origin (Figure $1 \mathrm{~B}$ and Supplemental Figure 1). Similar to the BALB/c mouse brains analyzed, $\mathrm{CD} 4^{+} \mathrm{T}$ cells represented the predominant $\mathrm{T}$ cell subset in the BLT mouse brain. Additional analysis of the human myeloid cell population in the brain demonstrated the presence of both classical $\left(\mathrm{CD} 14^{+} \mathrm{CD} 16^{-}\right)$and intermediate $\left(\mathrm{CD} 14^{+} \mathrm{CD} 16^{+}\right)$macrophages (Figure 1C). These results are consistent with those obtained from humans, nonhuman primates (NHPs), and WT mice and demonstrate that, in the absence of inflammation or any other stimulus, immune cells are present in the brain under normal conditions (46-51). 
Table 2. Quantitation of human hematopoietic cells by section in BLT mouse brains

\begin{tabular}{|c|c|c|c|}
\hline & & $\begin{array}{l}\text { Count per section } \\
\qquad( \pm \text { SEM) }\end{array}$ & $\begin{array}{l}\text { Count per cm² } \\
\quad( \pm \text { SEM) }\end{array}$ \\
\hline \multirow{3}{*}{$\begin{array}{l}\text { Human hematopoietic cells } \\
\text { (hCD45') }\end{array}$} & Cerebrum & $118 \pm 7$ & $668 \pm 63$ \\
\hline & Brain stem & $175 \pm 12$ & $769 \pm 88$ \\
\hline & Cerebellum & $52 \pm 3$ & $757 \pm 74$ \\
\hline \multirow{3}{*}{$\begin{array}{l}\text { Human T cells } \\
\left(\mathrm{hCD3^{+ } )}\right.\end{array}$} & Cerebrum & $40 \pm 7$ & $242 \pm 35$ \\
\hline & Brain stem & $48 \pm 7$ & $231 \pm 33$ \\
\hline & Cerebellum & $22 \pm 3$ & $360 \pm 41$ \\
\hline \multirow{3}{*}{$\begin{array}{l}\text { Human macrophages } \\
\text { (hCD68 })\end{array}$} & Cerebrum & $69 \pm 4$ & $411 \pm 19$ \\
\hline & Brain stem & $110 \pm 5$ & $507 \pm 23$ \\
\hline & Cerebellum & $38 \pm 3$ & $578 \pm 45$ \\
\hline
\end{tabular}

The numbers of $\mathrm{hCD} 45^{+}, \mathrm{hCD}^{+}$, and $\mathrm{hCD} 68^{+}$cells were counted in 4 serial sections of an uninfected BLT mouse brain and assigned to regions, as depicted in Figure 3A. The average number of human cells present in each section or per centimeter squared is reported as \pm SEM.

Steady-state levels of human immune cells in the brains of BLT mice. We next determined the total numbers of human cells present in the brains of perfused BLT mice ( $n=104$ mice), which collectively represent multiple human donor tissues ( $n=43$ donors). The total number of human immune cells present in the brains of BLT mice was determined using flow cytometry (Figure 2A). The number of human hematopoietic cells $\left(\mathrm{hCD} 45^{+}\right)$present in the brains of BLT mice was consistent across time after humanization surgery (Figure 2B). This analysis was repeated for human $\mathrm{T}$ cells (Figure $2 \mathrm{C}$ ), $\mathrm{CD}^{+} \mathrm{T}$ cells (Figure 2D), $\mathrm{CD} 8^{+} \mathrm{T}$ cells (Figure 2E), myeloid cells (Figure 2F), and B cells (Figure 2G); no relationship between the weeks after humanization surgery and the absolute number of any cell subset was noted. Additionally, we noted no significant change in the $\mathrm{CD} 4^{+} / \mathrm{CD} 8^{+}$ratio in the brain over time (Figure $2 \mathrm{H}$ ). We also found no correlation between the levels of human immune reconstitution in the peripheral blood or brain (Figure 2I). This suggests that a cellular steady state is established rapidly in the brain as the result of normal immune trafficking and immune surveillance of this tissue. We did note that an increased level of preconditioning irradiation (2.5 Gy versus 2.0 Gy) was associated with lower total numbers of human hematopoietic cells, myeloid cells, and B cells in the brain $(P=0.029, P=0.011$, and $P=0.049$, respectively, Supplemental Figure 2). Additionally, brains from female BLT mice had higher numbers of human B cells compared with that seen in male BLT mice ( $P=0.038$, Supplemental Figure 2$)$. The numbers of T cells and the $\mathrm{CD} 4^{+} / \mathrm{CD}^{+}$ratio were unaffected by sex or level of irradiation (Supplemental Figure 2).

Distribution of human immune cells throughout the brain. We performed immunohistochemistry (IHC) to determine the systemic distribution of human immune cells throughout the entire brain of BLT mice and found that human immune cells were present throughout the cerebrum, brain stem (consisting of the interbrain, midbrain and hindbrain), and cerebellum. These regions are outlined in Figure 3A. Specifically, we detected the presence of human hematopoietic cells $\left(\mathrm{hCD} 45^{+}\right)$, human $\mathrm{T}$ cells $\left(\mathrm{hCD}^{+}\right)$, and human macrophages $\left(\mathrm{hCD} 68^{+}\right)$from the olfactory bulb through the base of the brain stem in the medulla (Figure 3B), thus confirming that HIV target cells are present throughout the brains of BLT mice. Both $\mathrm{CD} 4^{+}$and $\mathrm{CD} 8^{+} \mathrm{T}$ cell subsets were present throughout the brains of BLT mice (Supplemental Figure 3), including the olfactory bulb, cerebral cortex, caudate putamen, thalamus, midbrain, pons, and cerebellum. Additionally, we quantitated the number of $\mathrm{hCD} 45^{+}, \mathrm{hCD} 3^{+}$, and hCD $68^{+}$cells in serial sections of an uninfected BLT mouse brain (Table 2). While the distribution of human hematopoietic cells and $\mathrm{T}$ cells was similar among the 3 regions $(P=0.3897$ and $P=0.0870)$, we detected a significantly greater number of human macrophages in the cerebellum compared with the number detected in the cerebrum $(P=$ 0.0264, Kruskal-Wallis test with Dunn's post test).

Dissemination of HIV from the periphery into the brain of BLT mice. To determine whether HIV traffics into and can establish infection in the brain, we infected BLT mice with one of several CCR5-tropic isolates or a CXCR4-tropic isolate (LAI). Of the CCR5-tropic isolates evaluated, 3 were T/F viruses (CHO4O, THRO, and RHPA), 1 was an early-passage strain (JR-CSF), and 1 was a laboratory-adapted macrophage-tropic virus (ADA). The animals were systemically infected after mucosal or parenteral exposure to virus, and 53 human donor tissues were represented. HIV DNA and/or HIV RNA levels in whole brains harvested from HIV-infected animals (as determined by the presence of HIV RNA in the peripheral blood) were quantified by real-time PCR. All 5 viruses tested were able to establish infection in the brains of BLT mice. Cell-associated HIV DNA was detected in $85.1 \%$ (57 of 67) of the brains from HIV-infected mice (Figure 4A). We found an inverse correlation between the levels of HIV DNA in the brain and the duration of infection $(P=0.0002$, Figure $4 \mathrm{~B})$. We detected cell-associated HIV RNA in $92.9 \%$ (104 of 112) of the brains from HIV-infected BLT mice (Figure 4C). To determine whether the route of infection (i.v., vaginal, or oral) influenced the levels of HIV in the brain, we analyzed 3 subsets of mice exposed via different routes. Our results showed no differences in the levels of HIV in the brain, regardless of the transmission route (all $P>$ 0.05 , Supplemental Figure 4A). We found an inverse correlation between the levels of HIV RNA and the duration of infection ( $P$ $<0.0001$, Figure 4D) and the weeks after humanization surgery $(P=0.0371$, Supplemental Figure 4B). Importantly, we observed a positive association between plasma viral load (VL) and the levels of cell-associated HIV RNA in the brain $(P<0.0001$, Figure $4 \mathrm{E})$. To confirm productive infection in the brain, we performed IHC to confirm HIV antigen expression in the brains of BLT mice infected with either JR-CSF (Figure 4F) or CHO4O (Figure 4G). We detected HIV p $24^{+}$cells in the cerebellum, thalamus, medulla, midbrain, and cerebral cortex. Together, these results demonstrate the ability of HIV to efficiently traffic into the brains of BLT mice and establish a productive and disseminated infection.

Analysis of the effect of HIV infection on human immune cell numbers in the brains of BLT mice. We determined the total numbers of human hematopoietic cells present in the brains of HIV-infected BLT mice ( $n=47$ human donor tissues represented) and compared them with the numbers present in the brains of uninfected mice (Figure 5A, left). We did not find differences in the overall number of human cells between infected and uninfected mice, regardless of the virus used for infection (Figure 5, left, and Supplemental 
A
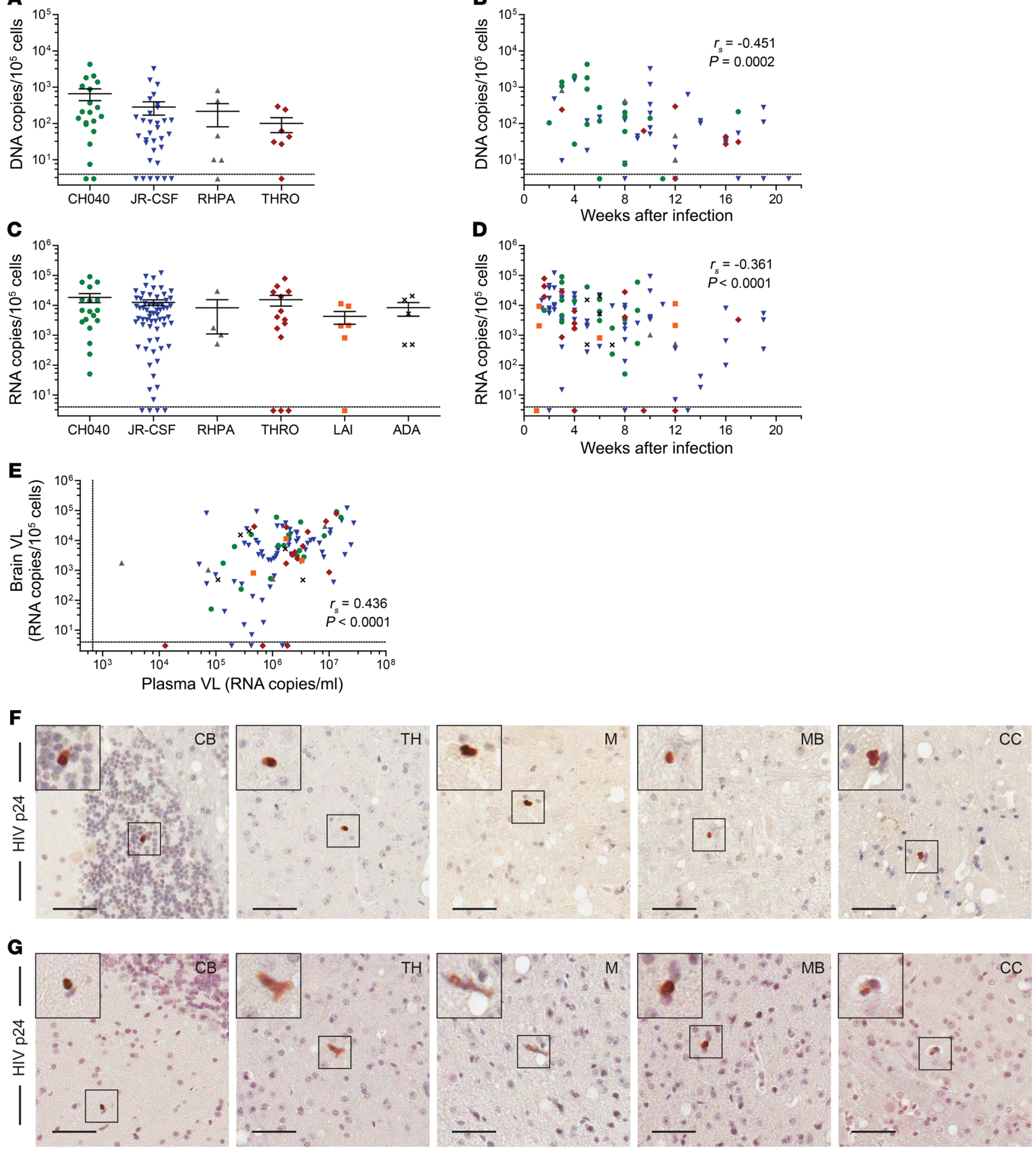

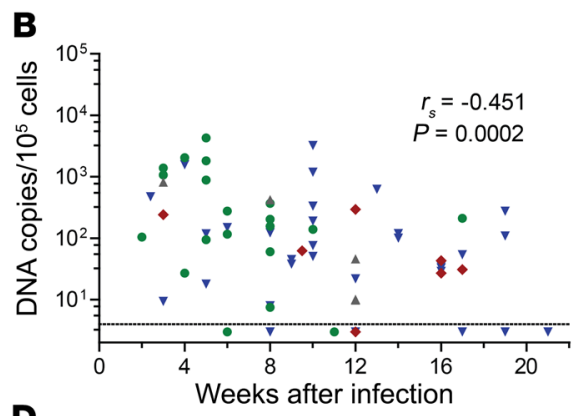

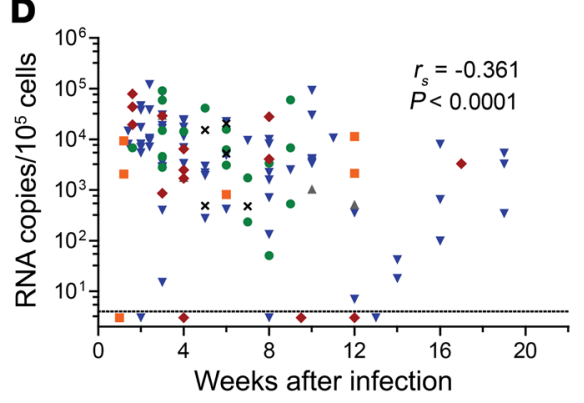

Figure 4. HIV is present in the brains of systemically infected BLT mice. (A) HIV DNA levels in the brains of BLT mice infected with 4 different HIV-1 isolates ( $n=20$ CH040, 32 JR-CSF, 6 RHPA, and 7 THRO). (B) Scatter plot indicates the time points after infection at which HIV DNA levels were determined in the brains of BLT mice. (C) HIV RNA levels in the brains of mice systemically infected with HIV ( $n=18$ CHO40, 65 JR-CSF, 4 RHPA, 14 THRO, 6 LAI, and 5 ADA). (D) Scatter plot indicates the time points after infection at which HIV RNA levels were determined in the brains of BLT mice. (E) HIV RNA levels in plasma of BLT mice at the time of necropsy, when HIV RNA levels in the brain were measured ( $n=112$ ). In A-E, the dashed horizontal lines represent the lower limit of detection for cell-associated HIV DNA and RNA ( 4 copies). In E, the dashed vertical line represents the lower limit of detection for the plasma VL ( 688 RNA copies/ml plasma). Immunohistochemical analysis revealed the presence of HIV p24+ cells (brown) in the brains of BLT mice infected systemically with HIV-1 JR-CSF (F) or CH040 (G). Scale bars: $50 \mu \mathrm{m}$. Original magnification, $\times 2$ (insets). A Spearman's rank correlation test was used for the statistical analysis of data in $\mathbf{B}, \mathbf{D}$, and $\mathbf{E}$, and $P$ values are shown in each graph. Horizontal lines in $\mathbf{A}$ and $\mathbf{C}$ indicate the mean \pm SEM. 
A

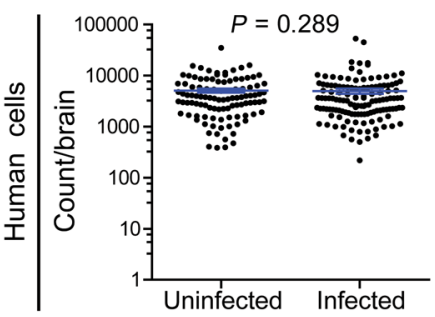

B

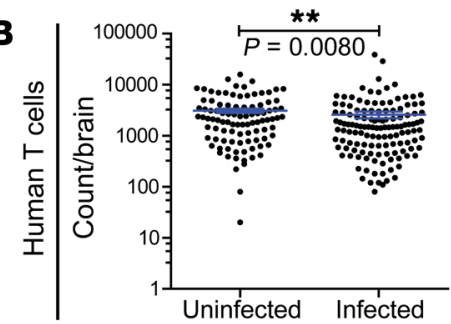

C

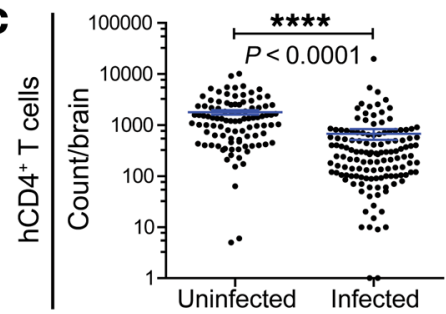

D

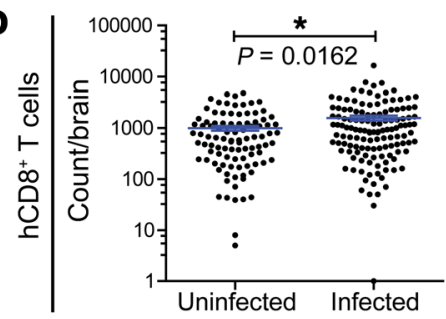

E

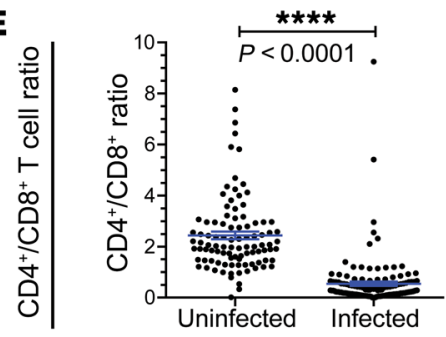

$\mathbf{F}$

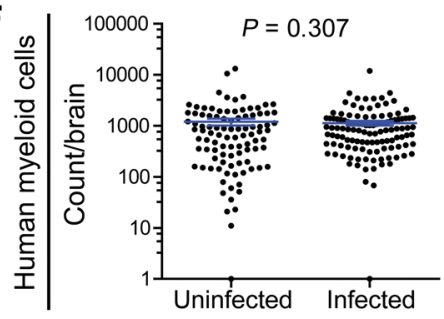

- $\mathrm{CH} 040$
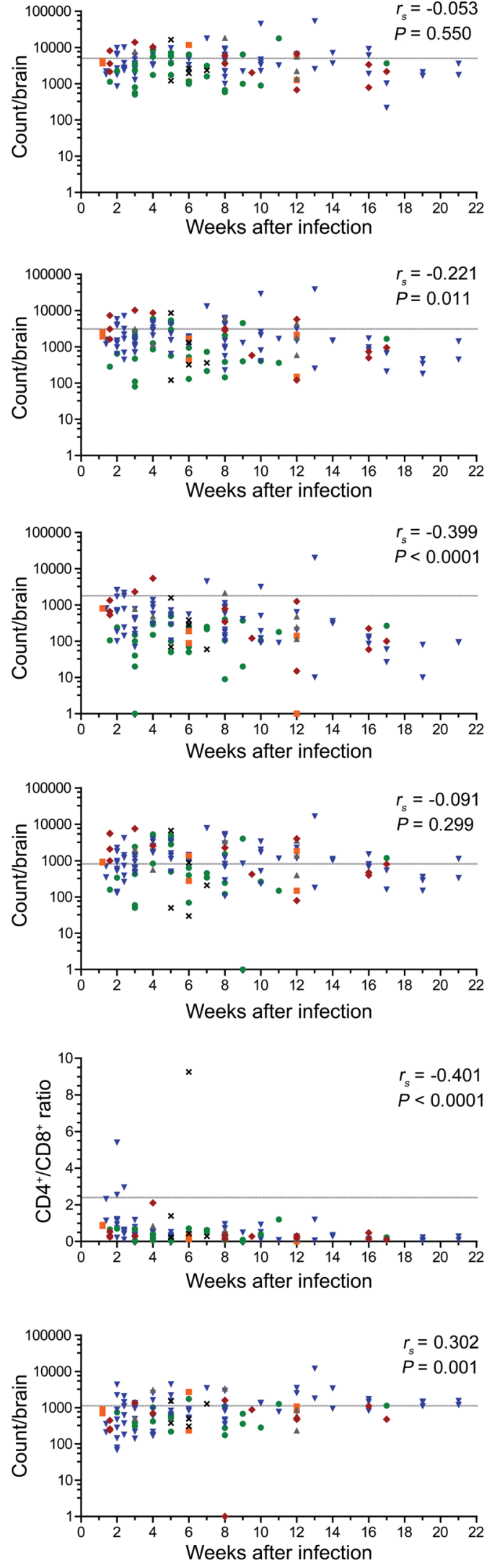

RHPA THRO $\square$ LAI $\times$ ADA

Figure 5. Alterations in human T cell populations in the brains of HIV-infected BLT mice.

Total numbers of human (A) hematopoietic cells (hCD45+), (B) T cells, (C) CD4 ${ }^{+} \mathrm{T}$ cells, (D) CD8 ${ }^{+} T$ cells, (E) the $\mathrm{CD}^{+} / \mathrm{CD} 8^{+} \mathrm{T}$ cell ratio, and the numbers of $(\mathbf{F})$ myeloid cells in the brains of HIV-infected $(n=132)$ or uninfected ( $n=$ 104, from Figure 3) BLT mice were determined by flow cytometry. Left panels indicate the absolute number of cells or $\mathrm{CD} 4^{+} / \mathrm{CD} 8^{+} T$ cell ratio in the brains of uninfected and HIV-infected BLT mice. Right panels indicate the absolute number of cells or $\mathrm{CD4^{+ }} / \mathrm{CD} 8^{+} T$ cell ratio in the brains of HIV-infected BLT mice and the time points after infection at which analysis was done. Mice infected with the same HIV strain are shown with the same color and symbol (CHO4O: green circles; JR-CSF: blue inverted triangles; RHPA: gray triangles; THRO: red diamonds; LAI: orange squares; ADA: black $x)$. Horizontal lines indicate the mean \pm SEM (A-F, left). ${ }^{*} P<0.05,{ }^{*} P<0.01$, and ${ }^{* * *} P<$ 0.0001 , by Mann-Whitney $U$ test for comparison of absolute cell numbers and $\mathrm{CD} 4^{+} / \mathrm{CD}^{+}$ $T$ cell ratios in the brains of uninfected and HIV-infected BLT mice (A-F, left). The correlation over time for each parameter was assessed using a Spearman's rank correlation test. $P$ values are shown on each graph. The dashed gray lines on the plots on the right represent the mean values for the uninfected group. 
Figure $5 \mathrm{~A})$. No temporal association was noted between the total numbers of human cells and the duration of infection (Figure 5A, right). We also conducted this analysis for human $\mathrm{T}$ cells, $\mathrm{CD} 4^{+} \mathrm{T}$ cells, $\mathrm{CD}^{+} \mathrm{T}$ cells, the $\mathrm{CD} 4^{+} / \mathrm{CD}^{+}$ratio, and myeloid cells (Figure 5, B-F, and Supplemental Figure 5, B-F). We detected significantly lower numbers of human $\mathrm{T}$ cells and human $\mathrm{CD} 4^{+} \mathrm{T}$ cells in the brains of HIV-infected mice $(P=0.0080$ and $P<0.0001)$, and this was associated with the duration of infection $(P=0.011$ and $P<0.0001$, Figure 5, B and C). We observed an increased number of $C D 8^{+} \mathrm{T}$ cells in the brains of HIV-infected mice $(P=0.0162$, Figure 5D), although there was no temporal correlation for this parameter. A significantly lower $\mathrm{CD} 4^{+} / \mathrm{CD}^{+}$ratio was observed in the brains of HIV-infected mice $(P<0.0001)$, and this was associated with the duration of HIV infection $(P<0.0001$, Figure $5 \mathrm{E})$. Notably, this ratio was inverted in animals infected for as little as 1 week. While we detected no statistically significant difference between the total numbers of myeloid cells in the brains of uninfected and HIV-infected mice, we found a positive association between the number of myeloid cells and the duration of infection $(P=0.001$, Figure 5F). Additionally, we noted an inverse association between the levels of human $\mathrm{T}$ cells, $\mathrm{CD} 4^{+} \mathrm{T}$ cells, and CD8 ${ }^{+}$ $\mathrm{T}$ cells in the brain and the time after humanization surgery in HIV-infected BLT mice (Supplemental Figure 6). Overall, these results demonstrate that HIV infection of the brain results in a rapid and sustained reduction in $\mathrm{CD}^{+} \mathrm{T}$ cells reminiscent of the loss of $\mathrm{CD}^{+} \mathrm{T}$ cells that occurs early after infection in mucosal tissues like those of the gut and female reproductive tract (52-55).

$T$ cells alone are sufficient to establish and maintain HIV infection in the brain. Using humanized MoM, which are devoid of human $\mathrm{T}$ cells, we demonstrated that human macrophages are sufficient for the seeding and persistence of HIV infection in the brain (32). The role of T cells in the establishment and maintenance of HIV infection in the brain has not yet been directly established. To address this important question, we used humanized $\mathrm{T}$ cell-only mice (ToM) (31). ToM are produced by implantation of human thymic tissue under the kidney capsule of preconditioned NSG mice. Unlike BLT mice and MoM, ToM are not transplanted with autologous human $\mathrm{CD} 34^{+}$cells. Therefore, the bone marrow of ToM is not reconstituted with human stem cells and does not produce human myeloid or B cells. Rather, ToM are systemically reconstituted exclusively with human T cells (31). First, we established the presence of human $\mathrm{CD}^{+}$and $\mathrm{CD} 8^{+} \mathrm{T}$ cells in the brains of ToM using flow cytometric and immunohistochemical techniques (Figure 6A). We then determined the presence of HIV RNA in cells obtained from the brains of ToM infected with JR-CSF. We chose this viral isolate, as we previously demonstrated that it is exclusively $\mathrm{T}$ cell tropic and does not replicate in vivo in human tissue macrophages (32). Our results revealed the presence of HIV RNA in the brains of HIV-infected ToM, indicating that $\mathrm{T}$ cells alone are sufficient to establish and maintain HIV infection in the brain (Figure 6B). We compared the total number of human cells between uninfected and HIV-infected ToM. Similar to the analyses performed on BLT mouse brains, the cell subsets analyzed for ToM included human hematopoietic cells, $\mathrm{T}$ cells, $\mathrm{CD} 4^{+} \mathrm{T}$ cells, $\mathrm{CD} 8^{+} \mathrm{T}$ cells, and the $\mathrm{CD}^{+} / \mathrm{CD}^{+}$ratio (Figure $6, \mathrm{C}-\mathrm{G}$ ). Significantly lower numbers of $\mathrm{CD}^{+} \mathrm{T}$ cells and a lower $\mathrm{CD} 4^{+} / \mathrm{CD}^{+}$ratio were noted in the brains of HIV-infected ToM compared with those in uninfected mice. The presence of HIV p24+ cells throughout the brain of an HIV-infected ToM, including the cerebellum, medulla, and cerebral cortex, showed productive infection and replication of HIV (Figure 6H). Fourteen human donor tissues were represented. Collectively, these results demonstrate that $\mathrm{T}$ cells are sufficient to establish and maintain HIV infection of the brain and that myeloid cells are not required to traffic HIV from the periphery into the brain.

Analysis of the impact of ART on HIV infection in the brain. Last, we investigated the efficacy of combination ART (cART) on HIV infection in the brains of BLT mice. Two triple-cART regimens were included in our study. The first consisted of emtricitabine, tenofovir, and raltegravir (FTC/TDF/RAL), and the second consisted of dolutegravir, rilpivirine, and emtricitabine (DTG/RPV/FTC). Four of these drugs (FTC, RAL, DTG, and RPV) have especially good penetration into the CNS of HIV-infected individuals, as indicated by drug levels in the $\operatorname{CSF}(2,56,57)$. Mice were treated with cART for 3 to 23 weeks prior to harvesting brain tissue, and 21 human donor tissues were represented. cART administration resulted in dramatically lower or undetectable amounts of HIV DNA and HIV RNA in the brain $(P<0.0001$ and $P<0.0001$, Figure $7, A$ and $B)$. Both regimens tested were highly effective at suppressing HIV RNA levels in the brain (Supplemental Figure 7, A and B). We noted no correlation between the VL in plasma and the low levels of residual cell-associated RNA present in the brains of ART-treated mice (Figure 7C and Supplemental Figure 7C). Specifically, in mice with a plasma VL below the limit of detection ( $<688$ copies/ml), HIV RNA was still detectable in the brains of 17 of 26 (65.4\%) animals. This suggests that, while cART effectively reduced HIV production in the brain, it was unable to fully suppress virus levels in this tissue. We also compared the absolute numbers of human hematopoietic cells, $\mathrm{T}$ cells, $\mathrm{CD} 4^{+} \mathrm{T}$ cells, $\mathrm{CD} 8^{+} \mathrm{T}$ cells, and myeloid cells in the brains of uninfected, HIV-infected/-untreated, and HIV-infected/ cART-treated BLT mice (Figure 7, D-I). No differences were noted in the total numbers of human hematopoietic cells, $\mathrm{CD}^{+} \mathrm{T}$ cells, or myeloid cells among the 3 groups. However, we found that the decrease in the total number of human $\mathrm{T}$ cells and $\mathrm{CD} 4^{+} \mathrm{T}$ cells as well as the decreased $\mathrm{CD}^{+} / \mathrm{CD}^{+}$ratio observed in HIV-infected/ -untreated mice (relative to uninfected animals) was restored in the HIV-infected/ART-treated mice. Together, these data indicate that the dramatic viral and cellular changes occurring in the brain as a result of HIV infection can be significantly mitigated by cART. Also notable was the efficacy of ART to reduce, but not eliminate, HIV from the brains of infected BLT mice.

\section{Discussion}

Understanding the impact of HIV infection on the brain is fundamentally important. It is associated with significant pathology and represents a potentially difficult-to-reach HIV reservoir. The study of HIV infection of the brain has been restricted, because it can only be accessed via noninvasive imaging, CSF sampling, and autopsy samples. Since longitudinal access to the brains of humans and mice is not generally possible, we conducted a largescale (>350 brain samples), cross-sectional analysis of the brain of humanized mice during HIV infection. This study includes multiple human donors, different viruses, and several routes of exposure in an attempt to represent the diversity present in the HIV-infected population at large. 
A

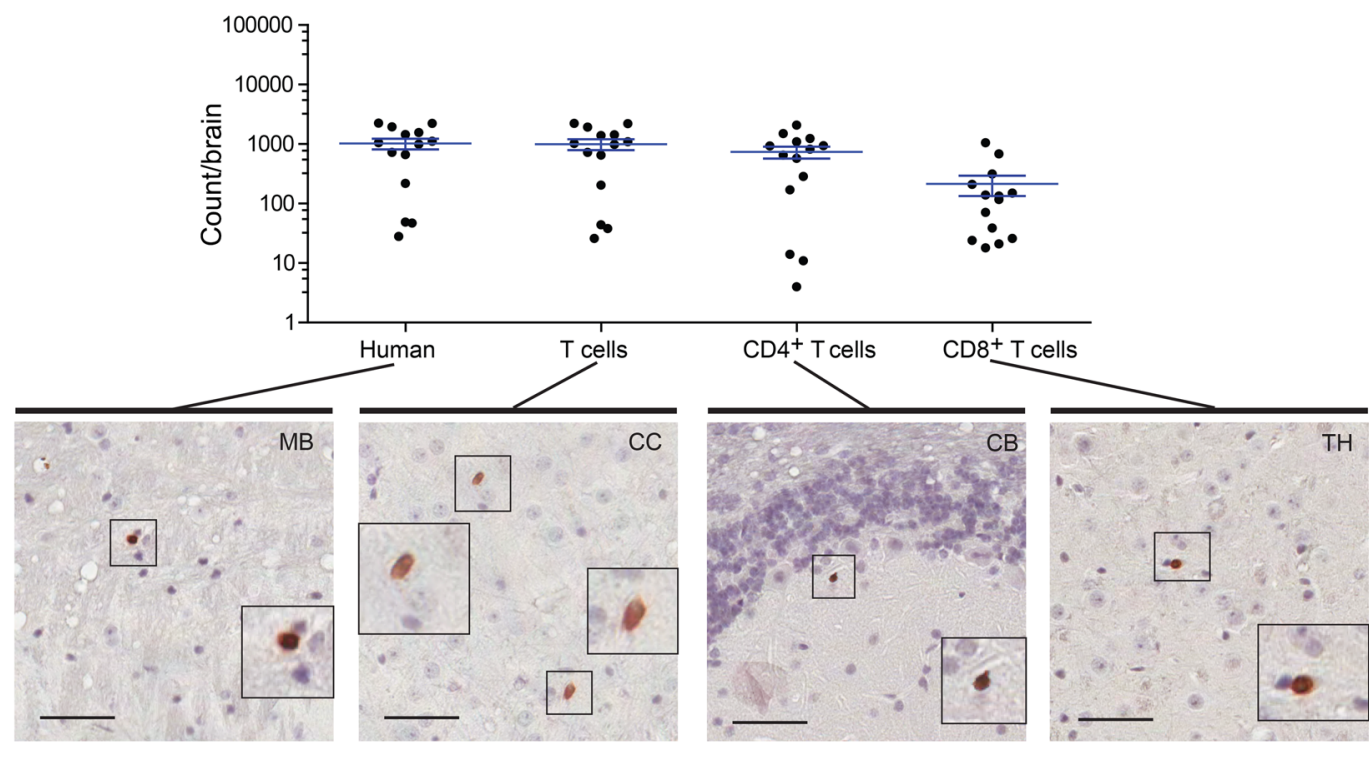

B

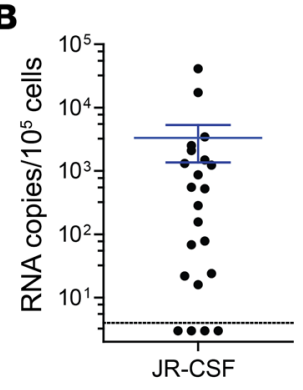

E

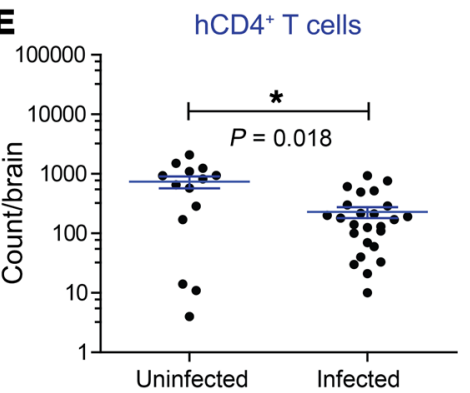

C

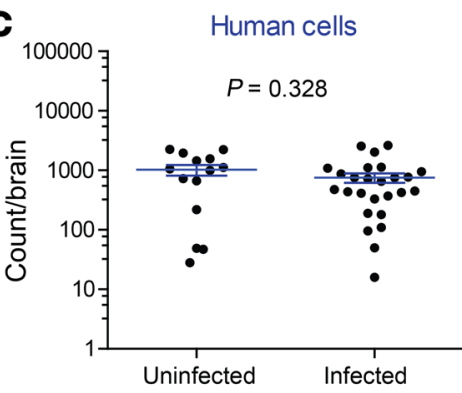

$\mathbf{F}$

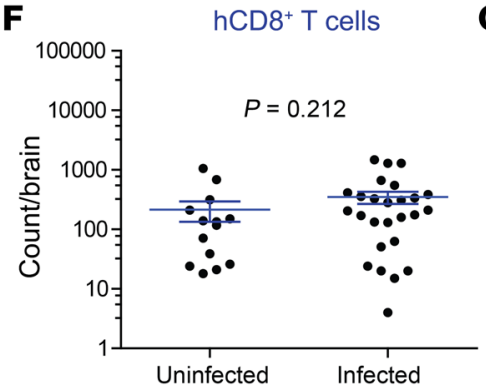

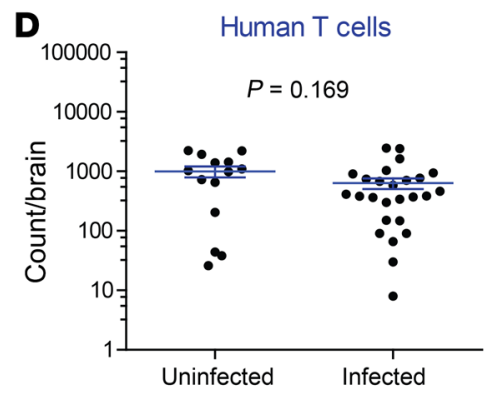

G $\quad \mathrm{CD}^{+} / \mathrm{CD} 8^{+} \mathrm{T}$ cell ratio

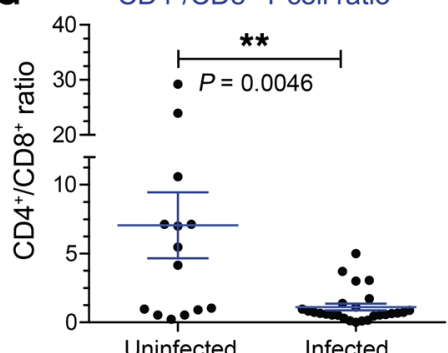

H

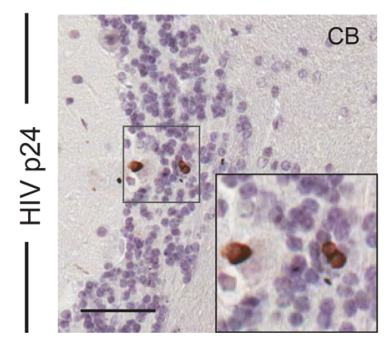

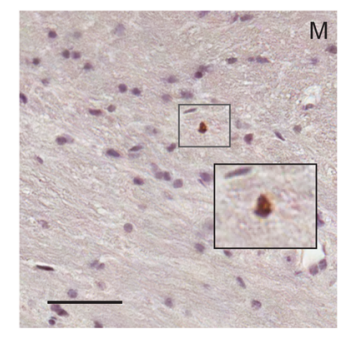

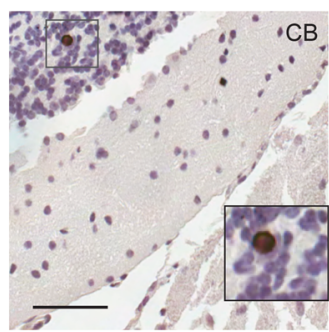

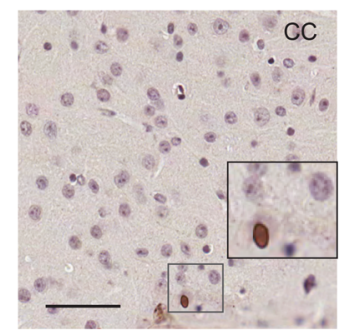

Figure 6. Human T cells are sufficient to establish HIV infection in the brain. (A) The numbers of human T cells in the brains of ToM were quantified using flow cytometry $(n=14)$, and the distribution of human cells was confirmed by staining brain sections with antibodies specific for hCD45, hCD3, hCD4, and hCD8 (positive cells are stained brown). (B) HIV RNA levels in the brains of ToM infected with T cell-tropic HIV-1 JR-CSF ( $n=22$ ). The dashed horizontal line represents the lower limit of detection for cell-associated RNA ( 4 copies). The numbers of human (C) hematopoietic cells, (D) T cells, (E) CD4 ${ }^{+}$T cells, and $(\mathbf{F}) \mathrm{CD}^{+} \mathrm{T}$ cells in the brains of uninfected $(n=14)$ and HIV-infected ToM $(n=26)$. (C) CD4 $/$ CD8 ${ }^{+} \mathrm{T}$ cell ratio in the brains of uninfected $(n=14)$ and HIV-infected ToM $(n=26)$. A Mann-Whitney $U$ test was used to analyze the data in C-C. ${ }^{*} P<0.05,{ }^{* *} P<0.01$. Horizontal lines in A-G indicate the mean \pm SEM. (H) Brain tissue sections from a systemically infected ToM were stained for HIV p24 ${ }^{+}$cells (brown). Scale bars: $50 \mu \mathrm{m}$. Original magnification, $\times 2$ (insets). 
A

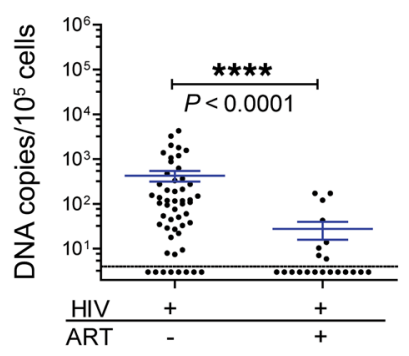

D

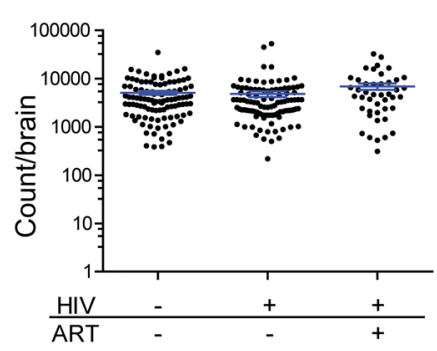

G

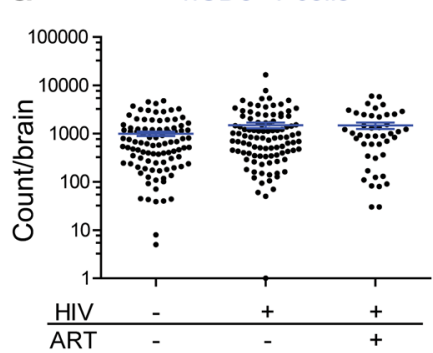

B

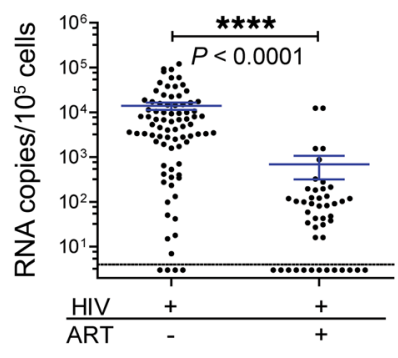

E

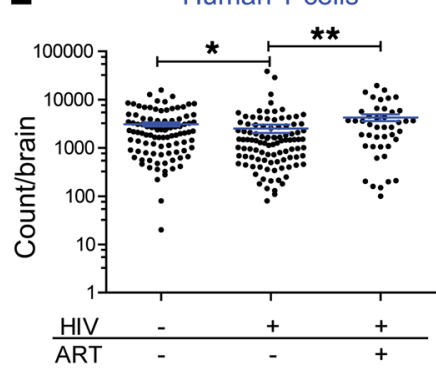

H

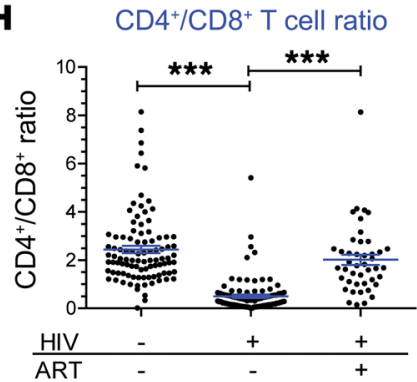

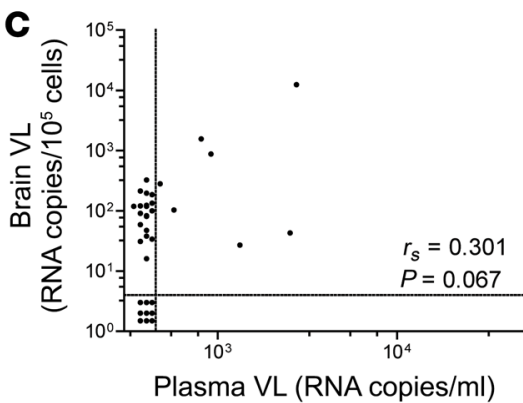

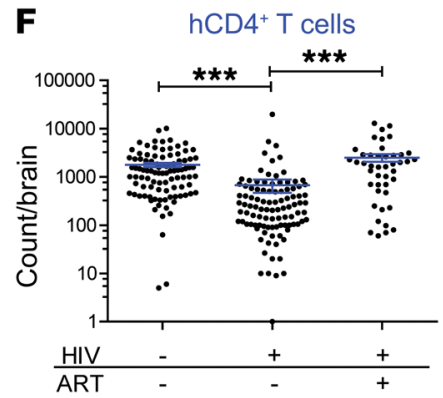

I Human myeloid cells

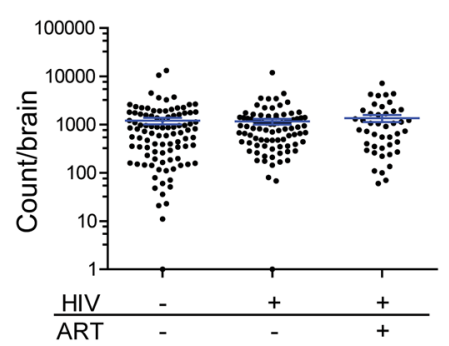

Figure 7. ART effectively controls HIV-1 infection in the brain of BLT humanized mice. (A) HIV DNA and (B) HIV RNA levels in the brains of HIV-infected/-untreated ( $n=52$ DNA, 82 RNA) and HIV-infected/ART-treated ( $n=17$ DNA and 36 RNA) BLT mice. Dashed horizontal lines represent the lower limit of detection for cell-associated DNA and RNA ( 4 copies). A Mann-Whitney $U$ test was used to compare data in A and B. (C) Scatter plot depicts the HIV RNA levels in the plasma and brains of HIV-infected/ART-treated BLT mice $(n=36)$. Dashed vertical line represents the lower limit of detection for the plasma VL ( 688 RNA copies/ml plasma). A Spearman's rank correlation test was used to analyze the data in C. Absolute numbers of human (D) hematopoietic cells ( $n=104,101$, and 44), (E) T cells ( $n=97,101,44)$, (F) CD4 ${ }^{+}$T cells $\left(n=97,101\right.$, and 44), (C) CD8 ${ }^{+}$T cells $\left(n=97,101\right.$, and 44), (H) the CD4 $/$ CD8 ${ }^{+}$T cell ratio ( $n=97,101$, and 44$)$, and (I) the numbers of human myeloid cells $(n=97,86$, and 44$)$ in the brains of uninfected (from Figure 3 ), HIV-infected/-untreated (from Figure 6), and HIV-infected/ART-treated mice were determined by flow cytometry. In D-I, the $n$ values for uninfected, HIV-infected/-untreated, and HIV-infected/ART-treated groups are indicated in parentheses from left to right. The data in $\mathbf{D}$-I were analyzed using a Kruskal-Wallis test, with Dunn's post test. ${ }^{*} P<0.05,{ }^{* *} P<0.01,{ }^{* *} P<0.001$, and ${ }^{* * *} P<0.0001$.

Our analysis of brains from WT mice provided a useful reference and demonstrated that during steady-state conditions, in the absence of any kind of inflammation or intentional disruption of the blood-brain barrier, hematopoietic cells normally traffic from the periphery and populate the brain. The presence of these cells in the brain is not likely due to blood contamination, since these mice were perfused prior to brain harvesting. Likewise, we found that the brains of BLT humanized mice were also reconstituted with human immune cells. Specifically, we were able to readily observe the presence of human T cells, B cells, and macrophages in the brains of BLT mice. These results demonstrate that, like endogenous mouse immune cells, human hematopoietic cells traffic from the periphery into the brain. The numbers of human hematopoietic cell populations in the brain were constant over time and did not correlate with the levels of human cells in periph- eral blood. Interestingly, human hematopoietic cells were distributed throughout many regions of the mouse brain including the olfactory bulb, cerebral cortex, caudate putamen, hippocampus, thalamus, midbrain, pons, medulla, and cerebellum. These data suggest that a steady state is reached in the brains of mice and that the cells present in both WT and BLT humanized mice represent normal immune surveillance of this tissue.

Macrophage infection in the brain is a hallmark of HIV disease and has been considered key to the pathogenesis associated with the neurological complications often observed in infected patients. Using MoM, we recently demonstrated the presence of macrophages in the brains of these animals and that these cells are sufficient to establish and maintain HIV infection in this tissue (32). However, in some cases, viruses isolated from the CNS do not exhibit macrophage tropism (10). Characterization of the viral tro- 
pism in CSF samples from 24 patients revealed the presence of R5 $\mathrm{T}$ cell-tropic viruses, with little or no ability to infect macrophages, suggesting that in these specific cases, the source of virus in the CNS was infected T cells (58). To determine whether infection of human $\mathrm{T}$ cells in the brain is dependent on the presence or trafficking of human macrophages, we exposed both BLT mice and ToM to HIV, which allowed us to examine T cell infection of the CNS in the presence or absence of human macrophages. ToM are devoid of human myeloid cells but are systemically repopulated with human T cells (31), thus providing a unique opportunity to investigate HIV infection in the brain in the absence of human macrophages. Our results demonstrate that all six HIV strains tested (five R5-tropic and one X4-tropic), regardless of the route of exposure (vaginal, oral, or parenteral), efficiently established infection in the brains of BLT mice. Evidence of HIV infection and replication in human T cells in the brains of BLT mice are supported by the fact that infection was established by three HIV-1 T cell-tropic isolates (JR-CSF, THRO, and RHPA) that do not replicate in macrophages (32). HIV was also readily found in the brains of ToM, demonstrating that $\mathrm{T}$ cells, in the absence of human macrophages, are sufficient for both the trafficking and establishment of HIV infection in this tissue.

HIV infection in the brains of BLT mice permitted the evaluation of its effect on human T cells and macrophages during the course of infection. HIV infection resulted in a rapid and sustained drop in the levels of human $\mathrm{CD} 4^{+} \mathrm{T}$ cells in the brain. The rapid and profound reduction in $\mathrm{CD}^{+} \mathrm{T}$ cells in the brain is highly reminiscent of what is observed in mucosal tissues like the those of the gut and female reproductive tract (52-55) and indicates that HIV can inflict damage to the immune system in the brain early after infection. Consistent with the progressive loss of human $\mathrm{CD}^{+} \mathrm{T}$ cells in the brain, we documented an inverse correlation between the duration of infection and HIV RNA and HIV DNA levels in the brain, suggesting that during the initial establishment of infection, when viremia is highest, high levels of virus are also present in the brain. Interestingly, consistent with our previous results in MoM, we did not notice a reduction in the levels of myeloid cells in the brains of HIV-infected BLT mice (32). Rather, we noticed an increase in the number of myeloid cells in the brains of infected mice over time. In autopsy samples from HIV-infected patients, the diffuse presence of $\mathrm{CD} 68^{+}$and $\mathrm{CD} 8^{+}$cells was noted in the deeper midline and mesial temporal structures of the brain, including the midbrain, pons, medulla, thalamus, hippocampus, and cerebellum (59). When HIV-associated dementia was also present, robust numbers of HIV $\mathrm{p} 24^{+}$cells were also noted in these regions. In our mice, we detected the presence of human target cells in these particular regions and the presence of virus and productively infected cells in the midbrain, medulla, thalamus, and cerebellum of mice exposed to HIV-1 JR-CSF (T cell-tropic) or CHO4O (macrophage-tropic).

ART has significantly decreased the incidence and severity of neurological complications associated with HIV infection. It was therefore important to determine the effect of ART on HIV replication and $\mathrm{CD} 4^{+} \mathrm{T}$ cell depletion in the brains of BLT mice. Our results show that ART efficiently suppressed HIV RNA and HIV DNA levels in the brain. However, we did not observe a correlation between plasma VL and HIV RNA levels in the brains of HIV-infected/ART-treated mice. Remarkably, we found that ART treatment had a significant $(P<0.001)$ effect on the levels of $\mathrm{CD} 4^{+}$
$\mathrm{T}$ cells in the brain. Specifically, the levels of $\mathrm{CD} 4^{+} \mathrm{T}$ cells in the brains of ART-treated mice were significantly higher than those in HIV-infected/-untreated mice. In fact, the levels of $\mathrm{CD} 4^{+} \mathrm{T}$ cells in the brains of ART-treated mice were indistinguishable from the levels detected in noninfected mice. As $\mathrm{CD}^{+} \mathrm{T}$ cells in the brain are thought to support learning behaviors $(20,21)$, restoration of the number of these cells could benefit the neurocognitive functioning of HIV-infected individuals. These results demonstrate that ART controls HIV infection in the brain and restores CD4 ${ }^{+}$ $\mathrm{T}$ cells to normal levels. We also show a persistence of HIV in the brains of treated animals, which will allow us to determine whether therapies designed to affect the persistent HIV reservoir systemically will have an impact on persistence in the CNS.

As with any study conducted using relevant animal models, there are several limitations to this work. One important limitation of this study is that we were unable to evaluate the potential contribution of microglia to the propagation or maintenance of infection in HIV-infected BLT humanized mice with or without ART treatment. Fate-mapping studies have revealed that microglia are derived from early precursor cells present in the yolk sac $(58,60,61)$, suggesting that human microglial cells might not be recapitulated in any current humanized mouse model. The presence of human microglia would be of importance when evaluating macrophage-tropic isolates, as they could support more robust viral replication and induce profound pathology in the surrounding tissue. However, the lack of human microglia should not affect the results obtained with T cell-tropic viruses. Another limitation of this and other humanized mouse models is the fact that the remaining cells present in the brain are of murine, not human, origin. However, the critical interactions between HIV proteins like Tat and Env have been shown to act on murine brain cells and induce pathological sequelae, even in the absence of human hematopoietic cells (62-64). Finally, the overall lifespan of mice is relatively short compared with that of humans. Therefore, we are unable to follow our animals over several years after infection. In humans, the transition of T cell-tropic CNS viruses to a macrophage-tropic entry phenotype generally corresponds with a longer time of infection, allowing for extensive replication within this compartment that leads to viral evolution (10, 13). The extent to which any humanized mouse model is able to recapitulate the full complexity of neuroAIDS has yet to be determined. However, the present study demonstrated $\mathrm{CD}^{+} \mathrm{T}$ cell depletion, a hallmark of HIV infection and disease progression, and the ability of ART to mitigate this depletion.

The human brain is an important site of HIV infection where virus can replicate and possibly seed long-lasting reservoirs. Our studies indicate that both T cells and macrophages (32) can be successfully and independently infected in this organ. The notion that macrophages alone are responsible for the seeding of HIV infection in the brain is not supported by the presence of $\mathrm{T}$ cell-tropic viruses in the CSF of patients (10) or in the brains of BLT mice and ToM. Even though infection of the brain can take place shortly after exposure, ART dramatically reduces viremia and $\mathrm{CD} 4^{+} \mathrm{T}$ cell depletion in the brain, which is consistent with the significant benefits of early treatment intervention. One issue that remains to be addressed is whether HIV-infected cells in the brain (macrophages, microglia, or $\mathrm{T}$ cells) represent persistent reservoirs 
capable of reigniting infection upon reactivation of virus within the CNS and, as such, should be targeted by future HIV cure approaches. Recent evidence in SIV-infected, ART-treated NHPs showed the presence of replication-competent virus in brain macrophages, suggesting that the brain can be a source of virus, despite treatment (65). However, it remains to be determined whether this is true of HIV infection in the human brain. Models like the BLT mouse, MoM, and ToM $(31,32,66,67)$ provide useful tools for addressing many questions regarding HIV infection of the CNS.

\section{Methods}

Generation of humanized mice. Humanized BLT mice and ToM were prepared by implanting human thymus and liver tissue into preconditioned 8- to 12-week-old NOD.Cg-Prkdc ${ }^{\text {scid }} \mathrm{Il}_{2} \mathrm{rg}^{\text {tm1wjl }} / \mathrm{SzJ}$ (NSG) mice (The Jackson Laboratory) $(30,31,33)$. The thymus and liver implants consisted of a 1- to 2-mm piece of liver tissue sandwiched between 2 pieces of autologous thymus that were placed under the left kidney capsule (Advanced Bioscience Resources). BLT mice were also given an autologous stem cell transplant containing approximately $3.5 \times 10^{5}$ $\mathrm{CD}^{+} 4^{+}$cells (cells isolated from the liver). The reconstitution of mice with human immune cells was monitored over time by polychromatic flow cytometric analysis of human $\mathrm{CD} 45^{+}$cells in peripheral blood, as previously described $(30,33)$. Whole peripheral blood was stained with antibodies, red blood cells were lysed, and the remaining cells were washed and fixed using a 1\% paraformaldehyde solution.

Brain harvesting from mice. Transcardial perfusion with $20 \mathrm{ml}$ of room-temperature PBS was performed at necropsy to minimize blood contamination within the brain. Heads were separated from the spine at the $\mathrm{C} 1$ vertebrate. The entire brain was collected, including the choroid plexus and brainstem, but the meninges were not included. All mice in Figures 1-6 were perfused; however, only 29 of 47 (61.7\%) of the ART-treated animals from Figure 7 were perfused. These animals were part of another study that required that the animals not be perfused. Brains were collected into $10 \mathrm{ml} \mathrm{HBSS}$ and processed as described previously (32). Whole brains or half brains (split into hemispheres, along the midline) were passed through a $70-\mu \mathrm{m}$ strainer, and mononuclear cells (MNCs) were isolated using a Percoll density centrifugation gradient. An average of $2 \times 10^{5} \mathrm{MNCs}$ were purified from whole-brain samples.

Flow cytometric analysis. Antibodies for flow cytometric analysis were purchased from BD Biosciences or BioLegend. The antibody panel used to analyze cells isolated from nonhumanized (BALB/c) mice included antibodies directed against mCD45 (APC, BD, catalog 559864 or APC-Cy7, BD, catalog 557659); mCD3e (PE-Cy7, BD, cata$\log 552774$ ); mCD19 (PE-Cy7, BD, catalog 553786); and mouse/human CD11b (PE, BioLegend, catalog 101207). The antibody panel used to analyze cells isolated from humanized mice included antibodies directed against hCD45 (APC, BD, catalog 555485 or APC-Cy7, BD, catalog 557833); hCD3 (FITC, BD, catalog 555339); hCD4 (APC-H7, BD, catalog 560158); hCD8 (PerCP, BD, catalog 347314); hCD19 (PE-Cy7, $\mathrm{BD}$, catalog 557835); hCD11b (PE, BD, catalog 555388 or APC, catalog 340937); hCD14 (FITC, BD, catalog 555397); hCD16 (PE-Cy7, BD, catalog 557744); and/or hCD33 (PE, BD, catalog 340679). Live cells were distinguished by their forward and side scatter profiles. Flow cytometric data were collected on either a BD FACSCanto or a BD LSRFortessa flow cytometer and analyzed using BD FACSDiva software (version 6.1.3). The count/brain was calculated on the basis of the total number of events for flow cytometric analysis in each sample and scaled according to the portion of the brain processed, stained, and analyzed. The gating scheme for all samples was live cells (forward scatter/side scatter [FSC/SSC]), and then either $\mathrm{mCD} 45^{++}$or hCD $45^{+}$cells.

Immunohistochemical analysis of brains. Brains for immunohistochemical analysis were harvested from BLT mice and fixed in $4 \%$ paraformaldehyde for 16 to 24 hours at $4{ }^{\circ} \mathrm{C}$. Whole brains were separated into half brains at the midline and cut into sagittal sections starting at the midline. Samples were then embedded in paraffin, cut into $5-\mu \mathrm{m}$ sections, and mounted onto poly-L-lysine-coated glass slides. Following paraffin removal, antigen retrieval (DIVA Decloaker, Biocare Medical, catalog DV2004), and blocking of nonspecific Ig-binding sites (Background Sniper, Biocare Medical), tissue sections were stained with primary antibodies overnight at $4^{\circ} \mathrm{C}$, probed with a biotin-free HRP-polymer system (MACH3 Mouse HRP-Polymer Detection, Biocare Medical), and developed with diaminobenzidine (ImmPact DAB Peroxidase Substrate, Vector Laboratories). All tissue sections were counterstained with hematoxylin. Primary antibodies directed against CD45 LCA (2B11 and PD7/26, Dako); CD3 (Sp7, Thermo Fisher Scientific); CD4 (SP35, Genway); CD8 (C8/144B, Dako); CD20 (L26, Biocare Medical); and CD68 (KP1, Dako) were used to identify the types of human cells present in the brains of humanized mice. HIV-infected cells were detected with an antibody directed against HIV p24 Gag (Kal-1, Dako). As a control, tissue sections were stained with either mouse IgG1k (Dako), mouse Ig2ak (Dako), or rabbit IgG (Dako) negative control antibodies. Light microscopy images were taken using an Aperio ScanScope XT (Leica Biosystems) with the assistance of the Translational Pathology Laboratory at UNC-CH. Representative images were acquired using Aperio ImageScope software.

HIV-1 analysis and exposures. PCR analysis for HIV gag was performed by first preparing genomic DNA from MNCs using QIAamp DNA blood mini columns (QIAGEN) according to the manufacturer's protocol. HIV RNA levels were monitored using a 1-step reverse transcriptase real-time PCR assay (TaqMan Assays-by-Design, ABI) according to the manufacturer's instructions (with primers 5 '-CATGTTTTCAGCATTATCAGAAGGA-3' and 5'-TGCTTGATGTCCCCCCACT-3'). Stocks of HIV-1 (JR-CSF, RHPA, THRO, LAI, ADA, and CH040) were prepared and titered as previously described (32). Briefly, virus supernatants were prepared via transient transfection of 293T cells and were titered using TZM-bl cells (an indicator cell line) as previously described (33). Animals were exposed i.v., rectally, vaginally, or orally to the various viral isolates. Inoculum doses (in tissue culture infectious units) by route of exposure were up to: $9 \times 10^{4}$ (i.v.), $5 \times 10^{6}$ (rectal), $3.6 \times 10^{5}$ (vaginal), and $1.4 \times 10^{6}$ (oral) $(30,33,52,68,69)$.

Antiretroviral treatment of humanized mice. For HIV treatment, we used 2 ART regimens. The first, FTC/TDF/RAL, is a previously described triple-combination of drugs that we have shown to be effective at suppressing the VL in ToM and BLT mice $(30,31,52,68)$. This regimen was administered by either daily injection or via a formulated rodent chow. The dosage of the injectable formulation was $212 \mathrm{mg} / \mathrm{kg}$ emtricitabine, $205 \mathrm{mg} / \mathrm{kg}$ tenofovir disoproxil fumarate, and $56 \mathrm{mg} /$ $\mathrm{kg}$ raltegravir (provided by Merck). The formulated FTC/TDF/RAL chow contained 1,500 mg emtricitabine, $1,560 \mathrm{mg}$ tenofovir disoproxil fumarate, and $600 \mathrm{mg}$ raltegravir per kilogram of pellets (Research Diets). The second regimen, DTG/RPV/FTC, was also a triple-combination therapy administered by daily s.c. injection. The dosage of this injectable formulation was $213 \mathrm{mg} / \mathrm{kg}$ emtricitabine, $8.8 \mathrm{mg} / \mathrm{kg}$ rilpivirine, and $17.6 \mathrm{mg} / \mathrm{kg}$ dolutegravir. 
Statistics. All data were graphed and analyzed using GraphPad Prism, version 5.04 (GraphPad Software). A line at the mean \pm SEM is shown in Figure 2A, Figure 4, A and C, and Figure 5 (left graphs), Figure 6, A-G, Figure 7, A, B, and D-I, Supplemental Figure 2, Supplemental Figure 4A, Supplemental Figure 5, and Supplemental Figure 7, A and B. The statistical tests used are indicated in the figure legends and/or text for each comparison performed. A $P$ value of 0.05 or less was considered statistically significant. For all Mann-Whitney $U$ comparisons (used in Figure 5,left graphs, Figure 6, Figure 7, and Supplemental Figure 2), a 2-tailed test was used. Spearman's rank correlation tests were used to determine direct or inverse associations between 2 parameters (used in Figure 2, Figure 4, Figure 5, right, Figure 7, Supplemental Figure 4B, Supplemental Figure 6, and Supplemental Figure 7C). To compare multiple groups at the same time, a Kruskal-Wallis test with Dunn's post test was used (in Figure 7, Supplemental Figure 4A, Supplemental Figure 5, and Supplemental Figure 7, and to compare data from Table 1). No adjustment was made for multiple hypothesis testing. No statistical methods were used to predetermine sample size, and no randomization was used.

Study approval. All mice were maintained in a specific pathogenfree facility at the Division of Comparative Medicine (DCM) of UNC$\mathrm{CH}$ according to protocols approved by the IACUC (protocols 15-168 and 15-174) of UNC-CH.

\section{Author contributions}

JBH designed the experiment, collected and processed brain samples from mice, prepared viral stocks, performed viral inoculations, performed flow cytometric analyses, and wrote the manuscript. BL provided data regarding WT mouse brains. CCN provided study materials and administered ART to mice. AW performed immunohistochemical staining of ToM brains and wrote the manuscript. RAC performed immunohistochemical staining of BLT mouse brains. WOT and SLB processed brain samples and performed flow cytometric analyses. MDS prepared and administered the DTG/RPV/FTC ART regimen to mice. PS participated in the study design and methods development. OZ, FP, JK, CLG, CE, and JJE participated in the study design and provided study materials. JVG conceived the study, designed and coordinated the study, and wrote the manuscript.

\section{Acknowledgments}

This work has been supported in part by grants from the National Institute of Allergy and Infectious Diseases (NIAID) (AI096113 and AI111899); the UNC CFAR (P30 AI050410); and by the National Institute of Mental Health (NIMH), NIH (MH108179). JBH was supported in part by a Virology Training Grant (T32 AI007419). BL was supported by grants from the Natural Science Foundation of Guangdong Province, China (2016A030310108) and the UNC-South China STD Research Training Center (1D43TW009532). AW was partially supported by a grant from the NIAID (1RO1 AI123010). Research reported in this publication was also supported in part by CARE, a Martin Delaney Collaboratory, of the NIAID, the National Institute of Neurological Dis-orders and Stroke (NINDS), the National Institute on DrugAbuse (NIDA), and the NIMH, NIH (1UM1AI126619) (to JVG). The funders had no part in study design, data collection/analysis, decision to publish, or preparation of the manuscript. We thank I. Chen for providing pYKJR-CSF (catalog 2708) and J. Kappes and C. Ochsenbauer for providing CHO4O (catalogs 11740, 1174, and 1175) via the AIDS Research and Reference Reagent Program. We thank Bonnie Howell and Stephanie Barrett (Merck \& Co.) for their assistance with raltegravir and antiretroviral-containing chow. We also thank former and current members of the Garcia laboratory, the husbandry technicians at the UNC DCM, the Immunology Core of the UNC CFAR, the Clinical Core of the UNC CFAR, and members of the Translational Pathology Laboratory and the Lineberger Comprehensive Cancer Center Animal Histopathology Core Laboratory for their support of this work.

Address correspondence to: J. Victor Garcia or Angela Wahl, Division of Infectious Diseases, Center for AIDS Research, University of North Carolina at Chapel Hill, School of Medicine, CB no. 7042, Genetic Medicine Building, 120 Mason Farm Rd., Chapel Hill, North Carolina 27599-7042, USA. Phone: 919.843.9600; Email: victor_garcia@med.unc.edu_(JVG). Phone: 919.843.9555; Email: awahl@med.unc.edu (AW).
1. Maschke M, Kastrup O, Esser S, Ross B, Hengge $\mathrm{U}$, Hufnagel A. Incidence and prevalence of neurological disorders associated with HIV since the introduction of highly active antiretroviral therapy (HAART). J Neurol Neurosurg Psychiatry. 2000;69(3):376-380.

2. Letendre SL, Ellis RJ, Ances BM, McCutchan JA. Neurologic complications of HIV disease and their treatment. Top HIV Med. 2010;18(2):45-55.

3. Heaton RK, et al. HIV-associated neurocognitive disorders persist in the era of potent antiretroviral therapy: CHARTER Study. Neurology. 2010;75(23):2087-2096.

4. Tozzi V, et al. Persistence of neuropsychologic deficits despite long-term highly active antiretroviral therapy in patients with HIV-related neurocognitive impairment: prevalence and risk factors. JAcquir Immune Defic Syndr. 2007;45(2):174-182.

5. Clifford DB, Ances BM. HIV-associated neurocognitive disorder. Lancet Infect Dis. 2013;13(11):976-986.

6. Aspelund A, et al. A dural lymphatic vascular sys- tem that drains brain interstitial fluid and macromolecules. JExp Med. 2015;212(7):991-999.

7. Louveau A, et al. Structural and functional features of central nervous system lymphatic vessels. Nature. 2015;523(7560):337-341.

8. Ochsenbauer C, et al. Generation of transmitted/ founder HIV-1 infectious molecular clones and characterization of their replication capacity in CD4 T lymphocytes and monocyte-derived macrophages. J Virol. 2012;86(5):2715-2728.

9. Salazar-Gonzalez JF, et al. Genetic identity, biological phenotype, and evolutionary pathways of transmitted/founder viruses in acute and early HIV-1 infection. JExp Med. 2009;206(6):1273-1289.

10. Sturdevant CB, Joseph SB, Schnell G, Price RW, Swanstrom R, Spudich S. Compartmentalized replication of R5 T cell-tropic HIV-1 in the central nervous system early in the course of infection. PLoS Pathog. 2015;11(3):e1004720.

11. Schnell G, Price RW, Swanstrom R, Spudich S. Compartmentalization and clonal amplification of HIV-1 variants in the cerebrospinal fluid during primary infection. J Virol. 2010;84(5):2395-2407.

12. Sturdevant $\mathrm{CB}$, et al. Central nervous system compartmentalization of HIV-1 subtype C variants early and late in infection in young children. PLoS Pathog. 2012;8(12):e1003094.

13. Bednar MM, et al. Compartmentalization, Viral Evolution, and Viral Latency of HIV in the CNS. Curr HIV/AIDS Rep. 2015;12(2):262-271.

14. Joseph SB, et al. Quantification of entry phenotypes of macrophage-tropic HIV-1 across a wide range of CD4 densities. J Virol. 2014;88(4):1858-1869.

15. Chan WL, Javanovic T, Lukic ML. Infiltration of immune $\mathrm{T}$ cells in the brain of mice with herpes simplex virus-induced encephalitis. J Neuroimmunol.1989;23(3):195-201.

16. Menendez CM, Jinkins JK, Carr DJ. Resident T cells are unable to control herpes simplex virus- 1 activity in the brain ependymal region during latency. JImmunol. 2016;197(4):1262-1275.

17. Fletcher JM, Lalor SJ, Sweeney CM, Tubridy N, Mills KH. T cells in multiple sclerosis and experimental autoimmune encephalomyelitis. Clin Exp 
Immunol. 2010;162(1):1-11.

18. Babbe $\mathrm{H}$, et al. Clonal expansions of CD8(+) T cells dominate the $\mathrm{T}$ cell infiltrate in active multiple sclerosis lesions as shown by micromanipulation and single cell polymerase chain reaction. JExp Med. 2000;192(3):393-404.

19. Brynskikh A, Warren T, Zhu J, Kipnis J. Adaptive immunity affects learning behavior in mice. Brain Behav Immun. 2008;22(6):861-869.

20. Radjavi A, Smirnov I, Kipnis J. Brain antigenreactive CD4+ T cells are sufficient to support learning behavior in mice with limited T cell repertoire. Brain Behav Immun. 2014;35:58-63.

21. Wolf SA, et al. CD4-positive T lymphocytes provide a neuroimmunological link in the control of adult hippocampal neurogenesis. JImmunol. 2009;182(7):3979-3984.

22. Glass WG, Lim JK, Cholera R, Pletnev AG, Gao JL, Murphy PM. Chemokine receptor CCR5 promotes leukocyte trafficking to the brain and survival in West Nile virus infection. J Exp Med. 2005;202(8):1087-1098.

23. Schrier RD, et al. Cerebrospinal fluid (CSF) CD8+ $\mathrm{T}$-cells that express interferon-gamma contribute to HIV associated neurocognitive disorders (HAND). PLoS One. 2015;10(2):e0116526.

24. Strazielle N, Creidy R, Malcus C, Boucraut J, Ghersi-Egea JF. T-Lymphocytes traffic into the brain across the blood-CSF barrier: evidence using a reconstituted choroid plexus epithelium. PLoS One. 2016;11(3):e0150945.

25. Young KG, Maclean S, Dudani R, Krishnan L, Sad S CD8+ $\mathrm{T}$ cells primed in the periphery provide timebound immune-surveillance to the central nervous system. JImmunol. 2011;187(3):1192-1200.

26. Smolders J, et al. Characteristics of differentiated CD8(+) and CD4 (+) T cells present in the human brain. Acta Neuropathol. 2013;126(4):525-535.

27. Catalfamo M, et al. CD4 and CD8 T cell immune activation during chronic HIV infection: roles of homeostasis, HIV, type I IFN, and IL-7. J Immunol. 2011;186(4):2106-2116.

28. Ribeiro RM. Dynamics of CD4+ T cells in HIV-1 infection. Immunol Cell Biol. 2007;85(4):287-294.

29. Connors M, et al. HIV infection induces changes in CD4+ T-cell phenotype and depletions within the CD4+ T-cell repertoire that are not immediately restored by antiviral or immune-based therapies. Nat Med. 1997;3(5):533-540.

30. Denton PW, et al. Generation of HIV latency in humanized BLT mice. J Virol. 2012;86(1):630-634.

31. Honeycutt JB, Wahl A, Archin N, Choudhary S, Margolis D, Garcia JV. HIV-1 infection, response to treatment and establishment of viral latency in a novel humanized T cell-only mouse (TOM) model. Retrovirology. 2013;10:121.

32. Honeycutt JB, et al. Macrophages sustain HIV replication in vivo independently of T cells. J Clin Invest. 2016;126(4):1353-1366.

33. Wahl A, et al. Human breast milk and antiretrovirals dramatically reduce oral HIV-1 transmission in BLT humanized mice. PLoS Pathog 2012;8(6):e1002732.

34. Honeycutt JB, Garcia JV. Humanized mice: models for evaluating NeuroHIV and cure strategies. J Neurovirol. 2018;24(2):185-191.

35. Honeycutt JB, Sheridan PA, Matsushima GK, Garcia JV. Humanized mouse models for HIV-1 infection of the CNS. J Neurovirol.
2015;21(3):301-309.

36. Tyor WR, Power C, Gendelman HE, Markham RB. A model of human immunodeficiency virus encephalitis in scid mice. Proc Natl Acad Sci U S A. 1993;90(18):8658-8662.

37. Persidsky Y, Buttini M, Limoges J, Bock P, Gendelman HE. An analysis of HIV-1-associated inflammatory products in brain tissue of humans and SCID mice with HIV-1 encephalitis. J Neurovirol. 1997;3(6):401-416.

38. Cook-Easterwood J, Middaugh LD, Griffin WC, Khan I, Tyor WR. Highly active antiretroviral therapy of cognitive dysfunction and neuronal abnormalities in SCID mice with HIV encephalitis. Exp Neurol. 2007;205(2):506-512.

39. Rao VR, et al. HIV-1 clade-specific differences in the induction of neuropathogenesis. J Neurosci. 2008;28(40):10010-10016.

40. Cook JE, et al. Highly active antiretroviral therapy and human immunodeficiency virus encephalitis. Ann Neurol. 2005;57(6):795-803.

41. Koneru R, Olive MF, Tyor WR. Combined antiretroviral therapy reduces brain viral load and pathological features of HIV encephalitis in a mouse model. J Neurovirol. 2014;20(1):9-17.

42. Wu X, et al. Brain invasion by CD4(+) T cells infected with a transmitted/founder HIV-1BJZS7 during acute stage in humanized mice. J Neuroimmune Pharmacol. 2016;11(3):572-583.

43. Araínga M, Su H, Poluektova LY, Gorantla S, Gendelman HE. HIV-1 cellular and tissue replication patterns in infected humanized mice. Sci Rep. 2016;6:23513

44. Asahchop EL, et al. Reduced antiretroviral drug efficacy and concentration in HIV-infected microglia contributes to viral persistence in brain. Retrovirology. 2017;14(1):47.

45. Kessing CF, et al. In Vivo Suppression of HIV Rebound by Didehydro-Cortistatin A, a "Blockand-Lock" Strategy for HIV-1 Treatment. Cell Rep. 2017;21(3):600-611.

46. Liu W, et al. Curcumin reduces brain-infiltrating $\mathrm{T}$ lymphocytes after intracerebral hemorrhage in mice. Neurosci Lett. 2016;620:74-82.

47. Mracsko E, Javidi E, Na SY, Kahn A, Liesz A, Veltkamp R. Leukocyte invasion of the brain after experimental intracerebral hemorrhage in mice. Stroke. 2014;45(7):2107-2114.

48. Bechmann I, Galea I, Perry VH. What is the blood-brain barrier (not)? Trends Immunol. 2007;28(1):5-11.

49. Greenwood J, Heasman SJ, Alvarez JI, Prat A, Lyck R, Engelhardt B. Review: leucocyte-endothelial cell crosstalk at the blood-brain barrier: a prerequisite for successful immune cell entry to the brain. Neuropathol Appl Neurobiol. 2011;37(1):24-39.

50 . Hickey WF. Basic principles of immunological surveillance of the normal central nervous system. Glia. 2001;36(2):118-124.

51. Bischoff T, Stahl-Hennig C, Mätz-Rensing K, Koutsilieri E, Sopper S. Definition of leukocyte subsets in primate central nervous system by polychromatic flow cytometry. Cytometry $A$. 2011;79(6):436-445.

52. Olesen R, et al. ART influences HIV persistence in the female reproductive tract and cervicovaginal secretions. JClin Invest. 2016;126(3):892-904.

53. Olesen R, Wahl A, Denton PW, Garcia JV. Immune reconstitution of the female repro- ductive tract of humanized BLT mice and their susceptibility to human immunodeficiency virus infection. J Reprod Immunol. 2011;88(2):195-203.

54. Mehandru S, et al. Primary HIV-1 infection is associated with preferential depletion of CD4+ T lymphocytes from effector sites in the gastrointestinal tract. JExp Med. 2004;200(6):761-770.

55 . Veazey RS, et al. Identifying the target cell in primary simian immunodeficiency virus (SIV) infection: highly activated memory CD4(+) T cells are rapidly eliminated in early SIV infection in vivo. JVirol. 2000;74(1):57-64.

56. Letendre SL, et al. ING116070: a study of the pharmacokinetics and antiviral activity of dolutegravir in cerebrospinal fluid in HIV-1-infected, antiretroviral therapy-naive subjects. Clin Infect Dis. 2014;59(7):1032-1037.

57. Mora-Peris B, et al. Rilpivirine exposure in plasma and sanctuary site compartments after switching from nevirapine-containing combined antiretroviral therapy. JAntimicrob Chemother. 2014;69(6):1642-1647.

58. Hashimoto D, et al. Tissue-resident macrophages self-maintain locally throughout adult life with minimal contribution from circulating monocytes. Immunity. 2013;38(4):792-804

59. Zhou L, et al. Evidence for predilection of macrophage infiltration patterns in the deeper midline and mesial temporal structures of the brain uniquely in patients with HIV-associated dementia. BMC Infect Dis. 2009;9:192.

60. Ginhoux F, Lim S, Hoeffel G, Low D, Huber T. Origin and differentiation of microglia. Front Cell Neurosci. 2013;7:45.

61. Ginhoux F, Jung S. Monocytes and macrophages: developmental pathways and tissue homeostasis. Nat Rev Immunol. 2014;14(6):392-404.

62. Paris JJ, Singh HD, Carey AN, McLaughlin JP. Exposure to HIV-1 Tat in brain impairs sensorimotor gating and activates microglia in limbic and extralimbic brain regions of male mice. Behav Brain Res. 2015;291:209-218.

63. Dickens AM, et al. Chronic low-level expression of HIV-1 Tat promotes a neurodegenerative phenotype with aging. Sci Rep. 2017;7(1):7748.

64. Mucke L, et al. Protection against HIV-1 gp120-induced brain damage by neuronal expression of human amyloid precursor protein. JExp Med.1995;181(4):1551-1556.

65. Avalos CR, et al. Brain macrophages in Simian Immunodeficiency Virus-infected, antiretroviral-suppressed macaques: a functional latent reservoir. MBio. 2017;8(4):e01186-17.

66. Garcia JV. In vivo platforms for analysis of HIV persistence and eradication. J Clin Invest. 2016;126(2):424-431.

67. Honeycutt JB, et al. HIV persistence in tissue macrophages of humanized myeloid-only mice during antiretroviral therapy. Nat Med. 2017;23(5):638-643.

68. Tsai $P$, et al. In vivo analysis of the effect of panobinostat on cell-associated HIV RNA and DNA levels and latent HIV infection. Retrovirology. 2016;13(1):36.

69. Chateau ML, Denton PW, Swanson MD, McGowan I, Garcia JV. Rectal transmission of transmitted/founder HIV-1 is efficiently prevented by topical $1 \%$ tenofovir in BLT humanized mice. PLoS One. 2013;8(3):e60024. 